\title{
Behind-the-Meter Compressed Air Energy Storage Feasibility and Applications
}

\author{
by \\ Anierobi Chioma Christiana \\ A thesis \\ presented to the University of Waterloo \\ in fulfilment of the \\ thesis requirement for the degree of \\ Master of Applied Science \\ in \\ Electrical and Computer Engineering
}

Waterloo, Ontario, Canada, 2019

(C) Anierobi Chioma Christiana 2019 
I hereby declare that I am the sole author of this thesis. This is a true copy of the thesis, including any required final revisions, as accepted by my examiners.

I understand that my thesis may be made electronically available to the public. 


\begin{abstract}
In many jurisdictions, commercial and industrial (C\&I) customers are charged for their energy consumption as well as the power drawn from the grid at peak load hours. In Ontario, the demand-based charge component of the electricity cost has been skyrocketing, and this cost often accounts for a significant portion of the overall operating cost of large customers. The Ontario Government in 2010 launched the Industrial Conservation Initiative (ICI) program which requires large customers (Class A) to pay a Global Adjustment (GA) charge, based on their percentage contribution in load during the top five system peak load hours over a one-year base period. This offers enormous savings opportunity to many industrial customers by using strategies to reduce or offset their load during these system peak load hours. However, managing demand can be challenging when faced with production constraints in areas of high-energy sensitive production lines where short interruptions are not permitted. Energy Storage System (ESS) offers the customer the capability to carry out its usual operations while simultaneously saving on the electricity bill through demand reduction. ESS can provide electricity to the facility during system peak periods to reduce the power drawn from the grid, while during non-peak price periods, the ESS is recharged by harnessing the low-cost power.

In this work, a detailed operations model of behind-the-meter Small Scale Compressed Air Energy Storage (SS-CAES) is developed for an industrial customer, with an existing well/cavern that can be re-purposed for air storage. The developed optimization model manages the operation of the CAES facility to minimize electricity costs, determining the storage energy output and the corresponding charging and discharging decisions of the SS-CAES system. Furthermore, a detailed economic analysis is carried out to examine financial viability of a practical behind-the-meter SS-CAES project. Some key parameters such as life cycle, CAES capacity and capital cost, and electricity price are considered for carrying out a sensitivity analysis, and the results suggest that SS-CAES is economically viable in the current Ontario rate structure. It is shown that the cost of an SS-CAES project and GA charges are the key determining factors for economic deployment of SSCAES in Ontario.
\end{abstract}




\section{Acknowledgements}

First, I give all glory to God almighty, the Author and Finisher of my faith, in whose hands I am but only a pencil. The Holy Spirit made the strength and opportunity to accomplish this thesis possible.

Then, I would like to passionately express my special appreciation and thanks to my supervisors, Professor Claudio Canizares and Professor Kankar Bhattacharya for their invaluable patience, kindness, motivation, guidance, encouragement and immense knowledge which were instrumental to the completion of this thesis. Your understanding and empathy through the toughest and my weakest moments in this my academic journey is priceless. Indeed, I feel lucky to have been under your tutelage as a student and I consider this opportunity the highest degree of privilege. I am grateful to Professor Magdy Salama and Professor Maurice Dusseault for reviewing my thesis and providing valuable comments and suggestions. I am also thankful to Professor Mehdad Kazerani and Professor Bissan Ghaddar for their insightful contributions during the formative stage of my research. Thanks to Professor Omar Ramahi for his time, encouragement and friendliness; sharing his academic life experiences strengthened me when life events made the journey a tough one for me.

I gratefully acknowledge the funding and support provided by Natural Sciences and Engineering Research Council (NSERC), Ontario Centre for Excellence, NRStor, Rocky Mountain Power, Ontario Power Generator, Union Gas, Compass Minerals, and Hydro One. Thanks to all of the members of the CAES in Salt Caverns research group at the University of Waterloo and special thanks to Katherine Peretick (NRStor) and David Paradis (Compass Minerals) for their generous help with data collection for this thesis.

My warmly thanks to my past and current colleagues in the Electricity Market Simulation and Optimization Laboratory (EMSOL) for providing such a friendly and pleasant work environment. Special thanks to a friend turned sister, Sreedevi Valsan Kandenkavil and her husband Nitin Padman for extending the hands of friendship when I needed it the most.

Words cannot express how grateful I am to my family especially my father- Samuel Nwankwo Emeka, my late mum - Agatha Emeka, step-mum - Imelda Emeka and my siblings - Uchenna, Ngozi, Chinwe, Onyinye, Ifeoma and Chimaobi. Your prayers for me was what sustained me especially in the darkest moments. I also appreciate my father-, mother-, and sister-in-laws who temporarily took care of the kids when I left for Canada. To my dear spouse, Anierobi Okechukwu, I feel like I owe it all to you, through thick and thin, you have been my backbone; taking care of our four kids all by yourself so I could pursue my dream. This sacrifice is priceless to me. In a very special way, I appreciate you 
my lovely daughter Munachimso Rita Anierobi, who at such a tender age assumed the role of a mother in my absence, taking care of the younger ones and yet excelling in her studies. I do not know how you do it but the challenge I feel by your efforts sustained me through the tough moments. To my other children - Arinze Bryan, Chimgozirim Emmanuella, Kamsiyochukwu Chibueze Emmanuel, thank you for staying strong for me; your excellent results and good reports from your teachers became a source of strength for me all through this academic journey.

As an international student, I appreciate the hospitality of Canadians towards making me comfortable to call Canada home and the support of the Federal and Ontarian governments towards my graduate-school funding. Thank you to the administrative staff of UW ECE department - Cassandra Brett, Brenda McQuarrie, Susan Widdifield, Aida Martinez, Jackie Leach, Sarah Landy etc., you are all amazing people. To all the students of St. John Paul II student centre at the St. Michael's Catholic Church, Waterloo whose generous donations made me spend Christmas with my Family in 2017; I am forever grateful for the kind of love you have shown me and special thanks to the Campus Minister of the centre, Joseph Godwin for all the uncountable supports especially spiritually; God bless you Joe.

A heartily thanks to the Lofrees' family - Glen and Yvette, their children and grandchildren who welcomed me into their family as one of them; providing me with the support one desires from one's immediate family and taking the burden of loneliness off my way, making sure I eat good meals and always asking how they can help. May the good Lord bless you all.

To all my Nigeria friends turned family, listing their names and contributions during this academic journey will take pages. I just want to say thank you. To those that I might have forgotten to mention, I am grateful for the support you gave to me 


\section{Dedication}

This is dedicated to the Holy Spirit my Greatest Friend. 


\section{Table of Contents}

List of Tables $\quad$ x

List of Figures $\quad$ xi

List of Acronyms xiii

Nomenclature $\quad$ Xv

1 Introduction $\quad 1$

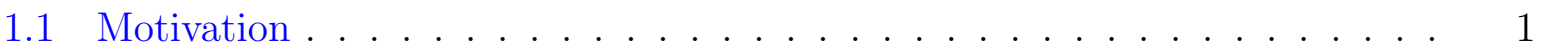

1.2 Literature Review . . . . . . . . . . . . . . . . . . 3

1.2.1 Compressed Air Energy Storage Applications . . . . . . . . . . . 3

1.2.2 Load Management of Customers . . . . . . . . . . . . 6

1.3 Research Objectives. . . . . . . . . . . . . . . . . 8

1.4 Outline of the Thesis . . . . . . . . . . . . . . . . 8

2 Background $\quad 10$

2.1 Energy Storage System Overview . . . . . . . . . . . . . . . . . 10

2.1.1 Classification of Energy Storage Systems . . . . . . . . . . . . . 12

2.1.2 Applications of Energy Storage Systems . . . . . . . . . . . 13

2.2 Compressed Air Energy Storage (CAES) . . . . . . . . . . . . . . 14

2.2.1 CAES Overview . . . . . . . . . . . . . . . 14 
2.2.2 Small-Scale Compressed Air Energy Storage (SS-CAES) $\ldots \ldots$.

2.3 Electricity Pricing . . . . . . . . . . . . . . . . . . . . . . . . . 18

2.3 .1 Ontario Electricity Pricing . . . . . . . . . . . . . . . . 18

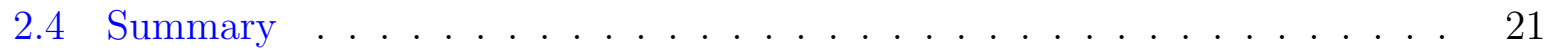

3 Optimal Operation of SS-CAES Systems for Customer Load Management 22

3.1 Framework . . . . . . . . . . . . . . . . . . . . . . . . . 22

3.2 Mathematical Model . . . . . . . . . . . . . . . . . . . . . . 24

3.2 .1 Objective Function . . . . . . . . . . . . . . . . . 24

3.2 .2 Model Constraints . . . . . . . . . . . . . . . . . . . 26

3.3 Results and Analysis . . . . . . . . . . . . . . . . . . . . . . . . 29

3.3 .1 Input Data . . . . . . . . . . . . . . . . . . . 30

3.3 .2 Results . . . . . . . . . . . . . . . . . . . . 35

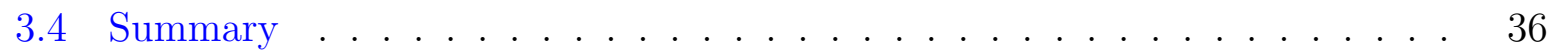

4 Economic Analysis of CAES Facility $\quad 37$

4.1 Economic Analysis . . . . . . . . . . . . . . . . . . . . . 37

$4.1 .1 \quad$ Basic Analysis . . . . . . . . . . . . . . . . . . . . . . 38

4.1 .2 Detailed Economic Analysis . . . . . . . . . . . . . . . . . . 41

4.2 Sensitivity Analysis . . . . . . . . . . . . . . . . . . . . . . 42

4.2 .1 Sensitivity to CAES Capacity . . . . . . . . . . . . . . 42

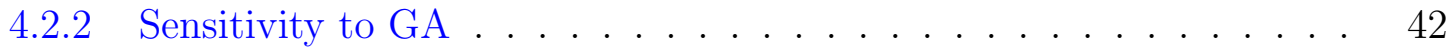

4.2 .3 Sensitivity to CAES Capital Cost . . . . . . . . . . . . . . 44

4.3 Comparison with BES . . . . . . . . . . . . . . . . . 48

4.4 Summary . . . . . . . . . . . . . . . . . . . . . . . 49

5 Conclusions, Contributions and Future Work $\quad 50$

5.1 Summary and Conclusions . . . . . . . . . . . . . . . . 50



5.3 Future Work . . . . . . . . . . . . . . . . . . . . . 52

viii 
References 


\section{List of Tables}

2.1 Potential Applications of Energy Storage Technologies [16] . . . . . . . . 15

2.2 Calculating GA charge - Example . . . . . . . . . . . . . . 20

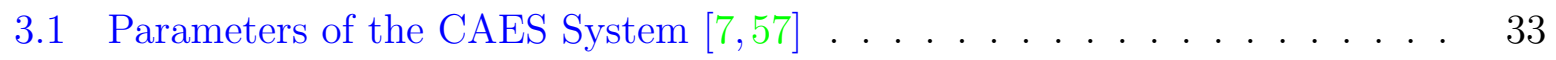

3.2 Cost Reduction for Different CAES Sizes . . . . . . . . . . . . . . . 34

4.1 Monthly Peak Demand of the Industrial Customer . . . . . . . . . . . . . . 39

4.2 CAES CAPEX Estimated . . . . . . . . . . . . . . . 39 


\section{List of Figures}

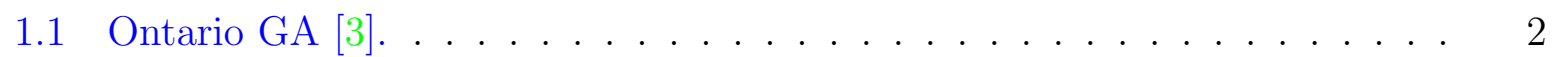

2.1 Basic components of a typical ESS [46] . . . . . . . . . . . . . 11

2.2 Classification of ESS technologies by form of stored energy [47]. . . . . . . 12

2.3 Classification of ESS technologies by functions [47] . . . . . . . . . . 13

2.4 Basic components of a CAES system [47]. . . . . . . . . . . . . 16

2.5 Classification of CAES based on heat management. . . . . . . . . . . 17

2.6 Real commodity cost (\$/MWh) $2005-2018 \ldots \ldots \ldots \ldots$

2.7 Industrial Conservation Initiative Cycle $[55] \ldots \ldots \ldots$

3.1 Proposed optimization process flow diagram. . . . . . . . . . . . . . 23

3.2 Schematic diagram of the facility load and CAES . . . . . . . . . . . 26

3.3 Energy balance of the CAES reservoir [53] . . . . . . . . . . . 28

3.4 Sample of one week HOEP. . . . . . . . . . . . . . . . . 30

3.5 Demand profile the industrial customer. . . . . . . . . . . . . . . 31

3.6 Annual load duration curve of the industrial customer. . . . . . . . . . . 32

3.7 Customer's load profile at the 5cp hours between May 2016 to April 2017 and $5 \mathrm{cp} \%$ occurrence between 2011 and $2017 \ldots \ldots \ldots \ldots . \ldots . \ldots . \ldots$

3.8 One week operation of the CAES dispatch model . . . . . . . . . . . . 35

3.9 Impact of CAES energy capacity on cost reduction. . . . . . . . . . . . 36

4.1 Linear plot to estimate intermediate CAES unit cost . . . . . . . . . 40 
4.2 IRR results obtained from basic economic analysis. . . . . . . . . . . . . . 40

4.3 IRR results of the detailed economic analysis . . . . . . . . . . . . . . 41

4.4 IRR results for $5 \%$ reduction in GAC . . . . . . . . . . . . . . . 43

4.5 IRR Results for $10 \%$ reduction in GAC . . . . . . . . . . . . . . . 43

4.6 IRR results for $15 \%$ reduction in $\mathrm{GAC} \ldots \ldots \ldots 4 . \ldots \ldots$

4.7 IRR results for $20 \%$ reduction in $\mathrm{GAC} \ldots \ldots \ldots \ldots$

4.8 IRR results for $25 \%$ reduction in GAC . . . . . . . . . . . . . 45

4.9 Result of CAPEX increases in the range of $2,000-3500 \$ / \mathrm{kW} \ldots \ldots$

4.10 Result of CAPEX increases in the range of $2,500-4,000 \$ / \mathrm{kW} \ldots \ldots$

4.11 Result of CAPEX increases in the range of $3,000-4,500 \$ / \mathrm{kW} \ldots \ldots . . .47$

4.12 Result of CAPEX increases in the range of $3,500-5,000 \$ / \mathrm{kW} \ldots \ldots 7$ 


\section{List of Acronyms}

5cp Five Coincident Peak.

BES Battery Energy Storage.

CAES Compressed Air Energy Storage.

C\&I Commercial and Industrial.

DOD Depth of Discharge.

DSM Demand Side Management.

ESS Energy Storage System.

FES Flywheel Energy Storage.

GA Global Adjustment.

HOEP Hourly Ontario Energy Price.

ICI Industrial Conservation Initiative.

IESO Independent Electricity System Operator.

IRR Internal Rate of Return.

LP Linear Programming.

MARR Minimum acceptable rate of return.

MILP Mixed Integer Linear Programming.

MINLP Mixed Integer Non-Linear Programming.

NPV Net Present Value. 
O\&M Operations and Maintenance.

PDF Peak Demand Factor.

PHS Pumped Hydro Storage.

RE Renewable Energy.

REV Revenue.

SMES Superconducting Magnetic Energy Storage.

SOC State of Charge.

TES Thermal Energy Storage.

TOU Time of use. 


\section{Nomenclature}

\section{Indices}

$h$

$d$

m

y

\section{Parameters}

CAPEX

Eini

$E^{\max }$

$E^{\text {min }}$

$E p_{d, h}$

FOMC

$N$

$M D T$

$O N D_{d, h}$

$P_{\text {comp }}^{\text {min }}$

$P_{\text {comp }}^{\max }$

$P D_{d, h}$

$P_{e x p}^{\min }$

$P_{e x p}^{\max }$

$P_{d, h}^{\text {gridmax }}$
Index for hours, $h=1,2, \ldots, 24$

Index for days, $d=1,2, \ldots, 365$

Index for months, $m=1,2, \ldots, 12$

Index for years, $y=1,2, \ldots, N$

\section{Capital cost of CAES [\$]}

initial level of air storage level $[M W h]$

Maximun energy capacity of the storage $[M W h]$

Minimum allowed level of air storage $[M W h]$

Hourly Ontario Energy Price $[\$ / M W h]$

Fixed O\&M cost of CAES [\%]

Project life [year]

Downtime for maintenance [\%]

Ontario system-wide demand at $5 \mathrm{cp}[M W]$

Minimum allowed charging power $[M W]$

Maximum allowed charging power $[M W]$

Hourly demand $[M W]$

Minimum allowed discharging power $[M W]$

Maximum allowed discharging power $[M W]$

Power supply from grid $[M W]$ 
TOMGAC $C_{m} \quad$ Total Ontario Monthly Global Adjustment [\$]

$V O M C_{\text {comp }} \quad$ Variable O\&M cost of Compressor $[\$ / M W h]$

$V O M C_{\text {exp }} \quad$ Variable O\&M cost of Expander $[\$ / M W h]$

$\eta_{\text {comp }} \quad$ Compressor efficiency [\%]

$\eta_{\text {exp }} \quad$ Expander efficiency [\%]

\section{Variables}

$E_{d, h}$

Energy level at each time step $[M W h]$

$E n C^{C A E S}$

Total annual energy cost of industrial customer with CAES [\$]

$E n C^{N o C A E S}$

Total annual energy cost of industrial customer without CAES [\$]

$G A C C A E S$

Total annual GAC of industrial customer with CAES [\$]

$G A C^{N o C A E S}$

Total annual GAC of industrial customer without CAES [\$]

$P_{d, h}^{C h}$

$P_{d, h}^{D C h}$

$P_{d, h}^{g r i d}$

Power consumption by CAES facility in charging mode [MW]

Power generation by CAES facility in discharging mode [MW]

Power drawn by the industrial customer from grid step $[M W]$

$S_{y}$

Total annual savings with CAES facility [\$]

SFOMC

Yearly fixed O\&M cost of CAES [\$]

SVOMC

Total annual CAES variable O\&M cost [\$]

$T C^{C A E S}$

$T C^{N o C A E S}$

Total annual electricity cost of industrial customer with CAES [\$]

$U_{d, h}^{C h}$

$U_{d, h}^{D C h}$

Total annual electricity cost of industrial customer without CAES [\$]

CAES facility in charging mode [0: OFF and 1: ON]

CAES facility in discharging mode [0: OFF and 1: ON] 


\section{Chapter 1}

\section{Introduction}

\subsection{Motivation}

Commercial and Industrial (C\&I) customers in many jurisdictions are not only charged for their energy consumption but also for the power they draw from the grid at peak hours [1,2]. For this category of customers, electricity prices have been skyrocketing, and this cost often represents a significant part of their overall operating budget, as in the case of many businesses in Ontario [1]. This rising price of electricity can be attributed to the Global Adjustment (GA) which is a charge imposed on the customers in Ontario since 2005 to cover the difference between the wholesale electricity market price and the electricity tariff rate paid to regulated and contracted generators, and to pay for conservation and demand management programs [3]. Since its inception, GA has been increasing significantly, as can be seen from Figure 1.1 [3].

The Industrial Conservation Initiative (ICI), which was introduced in 2010 by the Government of Ontario, requires large customers (Class A) to pay the GA charge based on their percentage contribution in load during the top five Ontario system peak load hours over a 12-month base period (May 1 to April 30) of the previous year [3]. This presents an enormous savings opportunity for many industrial customers by employing strategies to reduce or offset their load during these peak hours. While curtailing production during the system peak hours could save the customer a significant amount of the electricity cost, the challenge for the customer lies in balancing its monetary gain from load reduction at peak hours vis-a-vis the disruptive effect on its production.

As shown in Figure 1.1, the GA is continuing to increase year over year [4], and hence, managing the GA charge has become an increased priority for Class A customers. Many of 


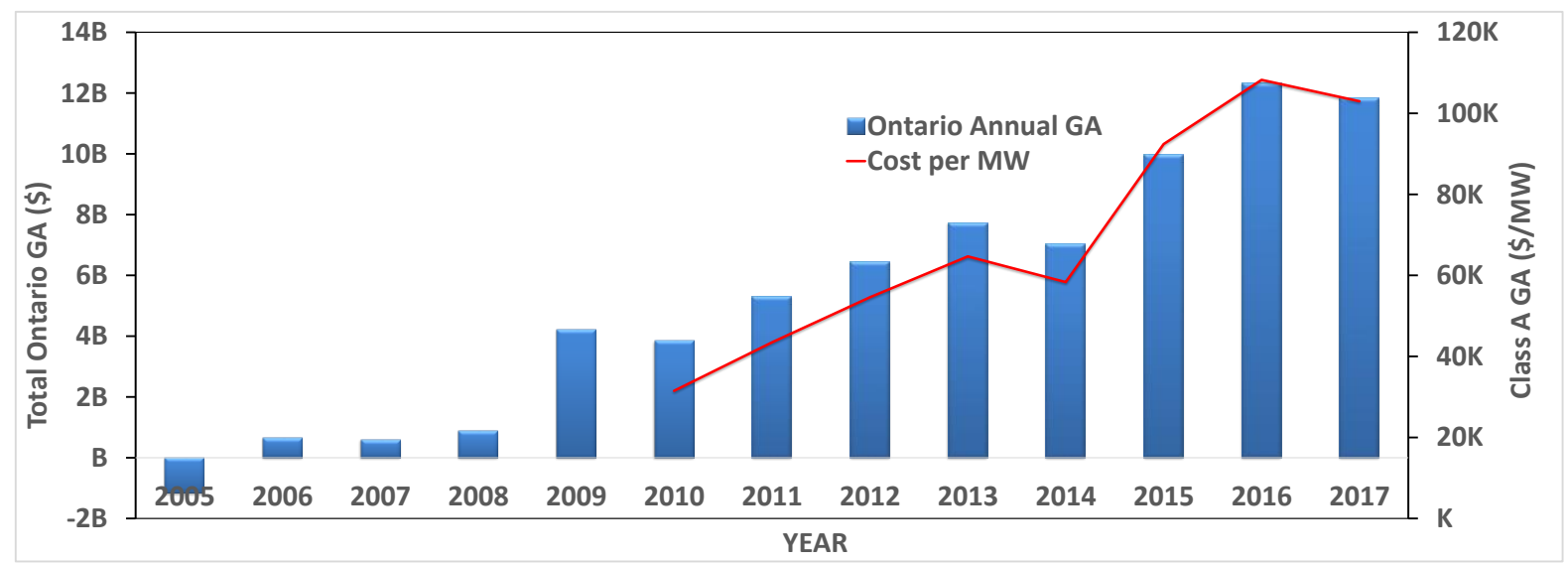

Figure 1.1: Ontario GA [3].

them are currently exploring innovative, energy-saving solutions; however, just how viable some of these techniques are, and at what cost would a budget-minded risk-averse business owner feel confident enough to take the leap, remains to be investigated. Some of the strategies that large customers can adopt towards reducing their load demand during the system peak hours and hence the electricity cost include [4]:

- Direct production curtailment

- Non-production baseload conservation and demand management

- Load-displacement through onsite generation

- Behind-the-Meter Energy Storage System (ESS)

For example, in Ontario, reducing the electricity demand during the five coincident peak (5cp) hours is often considered the most effective strategy, given the modest number of hours upon which the ICI program is based. However, direct production curtailment for the purpose of demand reduction would impact production, or result in not cutting enough load and missing the peak. Managing the demand can be challenging when faced with production constraints in areas of high energy sensitive production lines where short interruptions are not permitted. Utilizing back-up generators to reduce the demand is 
not a new idea; however, the customer must consider the extra expense of running the generators during peak hours and its impact on the environment and associated costs.

ESS is a not-so-new technology and is making waves as a promising option for load management when installed on the customer's facility to reduce electricity cost. The ESS can provide electricity to the facility during peak price periods to reduce the power drawn from the grid, while during non-peak price periods, the ESS would be recharged by harnessing the low-cost power. Battery energy storage (BES) is the dominating technology in the context of usage of behind-the-meter ESS for electricity cost savings [5]. Other technologies such as Compressed Air Energy Storage (CAES) have rarely been considered a viable option because of their location dependency and large capital cost for small scale installations [6]. However, CAES technology is a matured storage technology that has found applications at the grid scale level, and many researchers have reported that the capital cost of CAES decreases reasonably when empty wells/caverns exist that can be repurposed for air storage [7]. Hence, investigating the feasibility and economic viability of Small Scale CAES (SS-CAES) for an industrial facility with available empty wells/caverns for air storage, to defray the high peak-power electricity prices of Ontario, is the focus of this research work.

\subsection{Literature Review}

A brief and critical review of the literature pertaining to CAES applications and customer's load management is presented next.

\subsubsection{Compressed Air Energy Storage Applications}

CAES is one of the most promising and matured electrical energy storage technologies and has scope for extensive applications due to its favourable technological characteristics such as fast response capability, low cost, long service life, and low environmental impact [8,9]. CAES, just like any other storage technology, can be sited at the transmission system level, the distribution system level, or behind the customer's meter. Although CAES has received attention in recent years, in order to support their investment and deployment, investors and policy makers need an in-depth understanding of viable potential application of CAES technology. These are generally two-fold [10] :

- Utility scale for energy arbitrage, load balancing, smoothening the fluctuations arising 
from renewable energy sources, peak load shifting, emergency supply, and provision for black start in a power blackout situation.

- Behind the meter at the end-user side, for regulating the electricity drawn from the grid and hence to minimize their electricity cost, and enhance power quality and reliability.

Most of the early literature on CAES is centered on the technical description of CAES plant design for load leveling and fuel saving applications in combination with nuclear and coal-fired base load power plants [11-14]. The various potential applications of CAES systems are presented and discussed in [10,15-18]. CAES plants are designed to sustain frequent start-up/shut-down cycles, respond quickly and operate at part load levels with minimal performance penalties and thus are well-suited for regulation and load following [19]. Another significant use of CAES is energy arbitrage, which involves charging during the off-peak hours when prices are low, and then discharging when prices are high.

The authors in [20] carry out an extensive economic analysis of CAES and other ESS technologies based on their arbitrage potential in real-time US electricity markets, showing that, of all the ESSs, Pumped Hydro Storage (PHS) and CAES have the greatest potential for price arbitrage, and the return on investment is most impacted from reduction in the capital cost of PHS and CAES. The arbitrage value of ESS in the PJM market of USA is estimated in [21], noting that the decrease in the average price spread of energy with increasing penetration of renewable energy or ESS may lead to a decline of the arbitrage value of storage. As an alternative, different papers suggested complementing the arbitrage revenue stream with revenues from "additional" services as a crucial condition for CAES to achieve and maintain profitability [19,22]. In [23], a co-optimized CAES dispatch model is presented that quantifies the CAES potential in providing arbitrage, in addition to reserve services, in several US markets showing that only arbitrage-based revenues are unlikely to support CAES investment in most markets, but adding reserve revenues could support conventional CAES investments in several markets.

With increasing penetration of renewable energy (RE), CAES has been considered as a useful resource for facilitating RE integration into the power system. Thus researchers in [24] examines the technical development and financial plausibility of an advanced adiabatic CAES (AA-CAES) for wind energy integration in various European countries, and reports that the economic value of an AA-CAES increases significantly with increasing penetration of wind-power. A review of a large-scale CAES and wind hybrid energy system conducted in [25] demonstrates that CAES gave better performance in providing invariable dynamic 
wind power to the grid even at low wind speed compared to Flywheel Energy Storage (FES) system, and Superconducting Magnetic Energy Storage (SMES) system, etc.

Due to the proven technical advantages demonstrated by the large-scale CAES facilities in Germany and USA, researchers in [8,26-29] proposes and investigates different hybrid configuration of renewable-diesel-CAES systems. The focus of these works are mainly on the design, control strategies and technical feasibility of pairing CAES with other energy sources to compensate for the challenges associated with renewable and diesel energy supply. In [8], for example, a hybrid wind-diesel-CAES system deployed in a microgrid to supply a remote area in Canada is examined; small and medium scale CAES are considered, and by estimating the fuel consumption, greenhouse gas emissions and maintenance cost of diesel engines for different scenarios, it is noted that a wind-diesel-CAES hybrid system presents a significant potential for cost minimization and improved reliability of the microgrid.

Other use-cases of CAES at utility scale include transmission and distribution upgrade deferral and congestion relief. Thus in [30,31], the costs and benefits of deploying ESS for network investment cost reduction is explored by developing a transmission expansion model that incorporates ESS. The proposed model is applied to different test systems, and the results for all the test cases show that reduction of network investment cost is achievable by deploying ESS for the range of energy capacity considered.

At the end-user side, CAES technology is gaining significant interest among C\&I businesses as back-up power, on site renewable integration, and cost-effective solution to reduce the energy drawn from the grid and save on electricity costs. With today's evolving rate structures, falling price of solar and incentive programs, this market is forecast to grow rapidly [32], with SS-CAES being a potential resource in this context. Yet, some studies argue that CAES is not suitable for small scale application due to the sheer size of the installations and the associated costs [6]. Nevertheless, interest in SS-CAES is growing, with very few studies examining the techno-economic feasibility of such projects.

Although the use of CAES is not yet widespread, a significant amount of research works have analyzed its design, potential applications and economic viability for largescale applications. At the small-scale level, although there are several reported works on the design and modelling of CAES, works on the techno-economic feasibility are limited and therefore requires further attention and thus is the focus of the potential work. 


\subsubsection{Load Management of Customers}

In most utilities, C\&I customers are charged for both the energy they consume (kWh) and the load they impose on the utility during a billing period (kW demand). Such load contribution of the customer is generally determined by their percentage contribution to the system peak load, which are indicators for the utilities on the required capacity to meet the demand. For a large C\&I customer, a demand charge based on its demand coincident with the system peak demand can account for up to $50 \%$ of its monthly electricity bill [1]; a load management strategy is therefore of utmost importance to save on the electricity bill.

Load management of a customer encompasses schemes used to reduce its consumption during the system peak load hours. Strategies like charging of ESS units during off-peak periods for use during system peak hours, priority load scheduling to avoid large loads running simultaneously, rescheduling of processes, and use of own power production have been reported in [33] as the most common strategies of customer load management. System peak load reduction is beneficial to both the utility and the end-user $[5,33]$ and as such is becoming an important area of active research, thus motivating the work present here.

Use of local storage for peak shaving has been proposed as an alternative to C\&I customer's load management, especially where load curtailment poses a threat to the production line. In [34], BES is used to reduce the energy cost and hence the peak demand of the customer. A novel peak shaving scheduling problem is formulated in [2] using an optimal offline and a heuristic online algorithm to dispatch lossless and lossy batteries for peak reduction. By combining BES, smart meter and demand response (DR), the authors in [35] shift the load and smoothe the peak on a distribution feeder in New Mexico.

Optimum operation is a key challenge in peak shaving using ESS strategy, and to address this many studies have been carried out on the optimum operation of ESS. A control technique for BES state of charge (SOC) is developed in [36] by setting a demand limit, the ESS is charged when the demand is less than the demand limit and discharged when the demand is greater. A similar study on scheduling BES by setting demand limits for discharging of BES can be found in [37], keeping the charging times fixed night when the energy demand is low. A simple algorithm to control the BES SOC in real time is proposed in [38], while an adaptive control algorithm to manage the optimum operation of BES is presented in [39].

Optimal sizing of ESS is important to maximize a customer's return on investment and minimize the system losses. In view of this, the authors in [39] propose a novel ESS sizing method to obtain the optimum size of energy storage for C\&I customers, based on 
their historical load profile. Researchers in [34] propose the "Extrema" method to find the optimum size of BES for providing peak shaving services, where the objective function is calculated for a set of input values to optimize the size of BES. A model of BES sizing for peak load shaving based on a rolling method is propose in [40]; first, the energy capacity required to meet daily peak based on forecast daily load curve is evaluated, then the optimized size of BES is determined based on the evaluated result.

As high capital cost constitutes a major practical barrier for implementing ESS, many research works have studied the economic benefits of peak shaving, particularly for the consumer and the utility. From the customers' perspective, ESS used for peak shaving allows the customer to save on their electricity bill and carry out their daily activities simultaneously [5]. A mixed integer nonlinear programming (MINLP) model for minimizing the electricity cost and reducing the peak demand by rescheduling the loads, while satisfying the facilities operating constraints, is proposed in [41]; the case study of a typical caustic-chlorine plant shows that a reduction of about $19 \%$ in the peak demand, with a corresponding saving of about $3.9 \%$ in electricity costs is possible with the optimal load scheduling under time-of-use (TOU) tariff. In [42], an economic analysis of behind-themeter ESS is presented, formulating first a non-linear optimization problem to find the optimal operating scheme for ESS to minimize the monthly electricity cost of the customer; the problem is then transformed to a linear programming (LP) problem using the minimax technique, and case studies for customers in San Francisco were conducted. The results show that ESS can significantly reduce electricity costs by peak shaving and load shifting for the commercial customer, and by storing excess renewable energy for the residential customer. Optimal benefit and sizing of BES for behind-the-meter applications are evaluated in [32], in which the cost of energy and peak demand charge reduction for commercial buildings are co-optimized. In [43], an optimal demand charge management for TOU customers using ESS is discussed. The study in [44], performs a cost-benefit analysis for an industrial customer in South Korea that, uses ESS for peak reduction; Actual demand profiles of the industry are used to verify the effectiveness of the proposed ESS operation and estimate the savings in electricity costs.

The main advantage of a behind-the-meter ESS over other peak shaving strategies is that the customer is able to carry out its usual daily activities while simultaneously saving on the electricity bill through demand reduction. Among the various ESS, BES technology is the dominating choice for peak shaving application [5]. Consequently, there is a knowledge gap filled here in the domain of feasibility and economic analysis of other storage technologies like SS-CAES, and how it compares with BES for customer load management. 


\subsection{Research Objectives}

From the aforementioned literature review, it is noted that peak demand based rate structures, adopted by many utilities, calls for load management strategies to enable large C\&I customers save on electricity costs. An ESS located on a customer's facility, has been identified as one of the viable options for managing its load, especially in high energy intensive industries where power interruptions can be costly. However, since most of the works reported in this area focus on BES technology [5], there is a need to study the application of other ESS technologies as an alternative option.

Although SS-CAES can serve the purpose of customer's load management, most of the research works have focused on using above-ground storage vessels. Underground storage based SS-CAES is technically feasible, but not much work has been devoted to their economic viability, especially in the context of re-purposing an existing underground storage well/cavern, which can result in a significant reduction in capital costs [7]. Coupling this with the possible savings in cost of electricity in Ontario, SS-CAES is studies here a possible option for load management in an industrial facility with an existing well for air storage. In view of this, the objectives of this thesis are as follows:

- Develop a mathematical model for the coordinated operation of an industrial customer's facility equipped with a behind-the-meter SS-CAES. The optimization problem will seek to determine the minimum electricity cost operation, the storage energy output and corresponding charging and discharging decisions of the SS-CAES unit over the planning horizon.

- Perform a detailed economic analysis of different behind-the-meter SS-CAES system capacities to determine the optimal SS-CAES capacity that meets the investor's minimum acceptable rate of return.

- Perform a sensitivity analysis of the interactions between financial viability of SSCAES project and some key parameters influencing the project performance (life cycles, energy, and power prices).

\subsection{Outline of the Thesis}

The background required for the development of the research work is presented in Chapter 2. A detailed operational model of SS-CAES installed at customer's facility for load 
management is developed in Chapter 3; presenting and discussing the optimal operation results obtained.

To evaluate the financial plausibility of an SS-CAES project to an investor, an economic model is developed in Chapter 4. The developed model is subjected to a sensitivity analysis, and the detailed results are presented and discussed. Finally, in Chapter 5, the summary and conclusions from the research work are presented while highlighting the main contributions of the research. Future research directions are also discussed in this chapter. 


\section{Chapter 2}

\section{Background}

This chapter presents a brief overview of some of the background topics pertaining to the research in this thesis. First a general overview of ESS including the various types, components and applications at different levels in the power system is presented. Then, an overview of CAES systems, highlighting its main components, operating principles and use cases are discussed, followed by a brief overview of SS-CAES. Finally, electricity pricing in Ontario is discussed, providing details on the prevailing GA charges.

\subsection{Energy Storage System Overview}

The fundamental premise of ESS involves converting one type of energy (mainly electrical energy) into another, for the purpose of storage [45]. This stored energy is then reconverted into electrical energy for use when demand arises. An ESS, as depicted in Figure 2.1, commonly comprises four major components, which includes the following [46]:

- Storage Medium: This is a means or system in which energy is stored such as battery, CAES reservoir, flywheel or reservoir for pumped hydro systems. It sets the basic storage capacity limits.

- Charging System: Flow of energy from the electrical network to the storage medium occurs through this system. For example, in the CAES system, a compressor is driven by electricity to compress air for storage. 
- Discharging System: This system converts the stored energy to a readily usable form when demanded. The quality and quantity of power provided by the ESS is determined by this component. For a conventional CAES system, the expander performs this function.

- Control System: The entire operation of the ESS is coordinated by this system.



Figure 2.1: Basic components of a typical ESS [46]. 


\subsubsection{Classification of Energy Storage Systems}

Several methods have been suggested for categorization of various ESS technologies: form of energy stored, functions of the storage, duration of storage, and response time. The form and function are the most widely used methods $[45,47]$ for ESS classification.
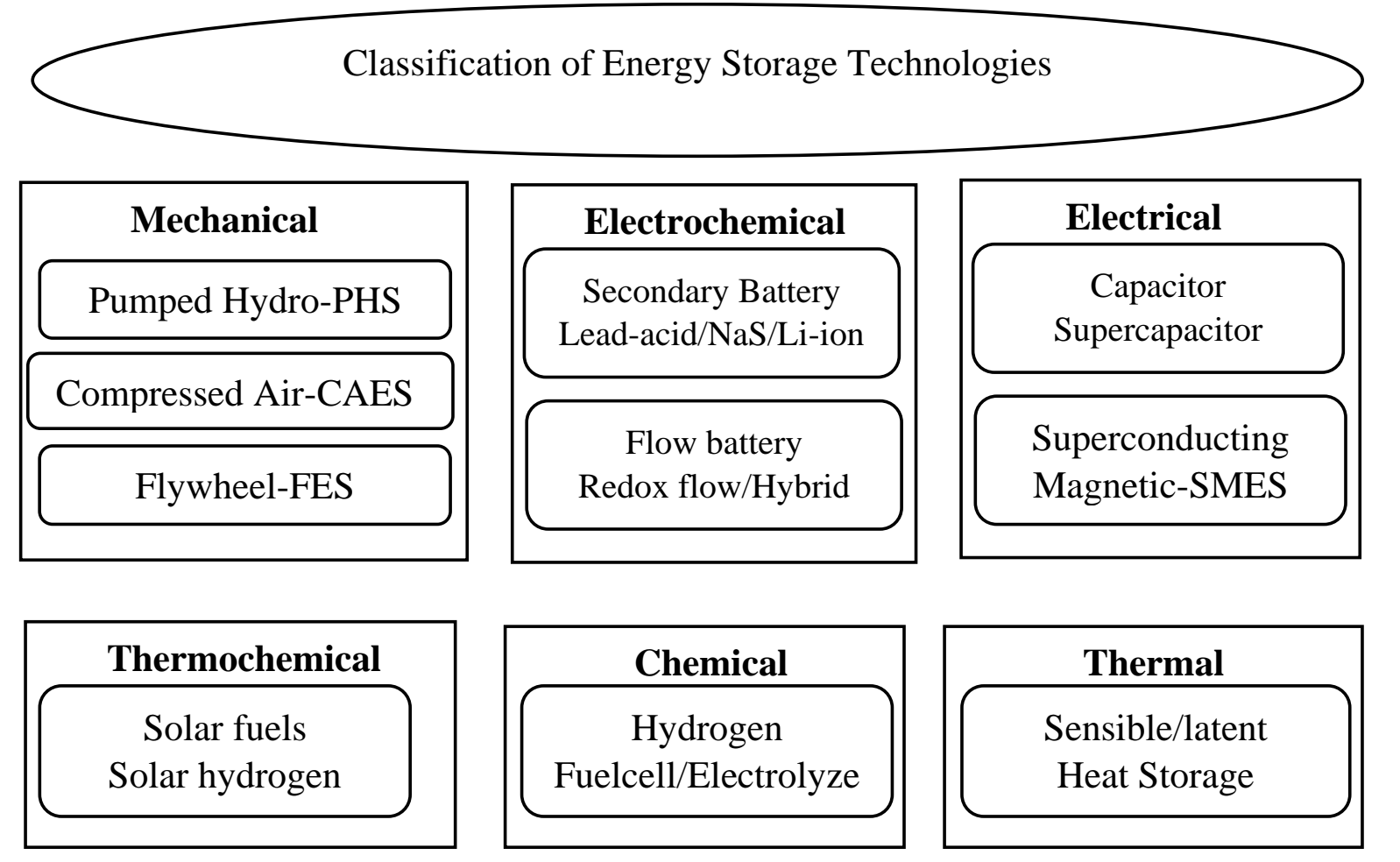

Figure 2.2: Classification of ESS technologies by form of stored energy [47].

Figure 2.2 shows the categorization of ESS in terms of form of energy stored in the system. A detailed description of each type of ESS is presented in [45,47]. In terms of their function, ESS can be categorized into those with high power ratings but relatively small energy content, making them appropriate for power quality and reliability applications; and those intended for energy management [45]. Figure 2.3 illustrates the ESS categories in terms of the functions.

Selection of an appropriate technology requires a critical analysis of the fundamental features of the storage systems to establish a reasonable comparison criteria. The discharge duration, power and energy densities, and cycle efficiency are some of the characteristics of 


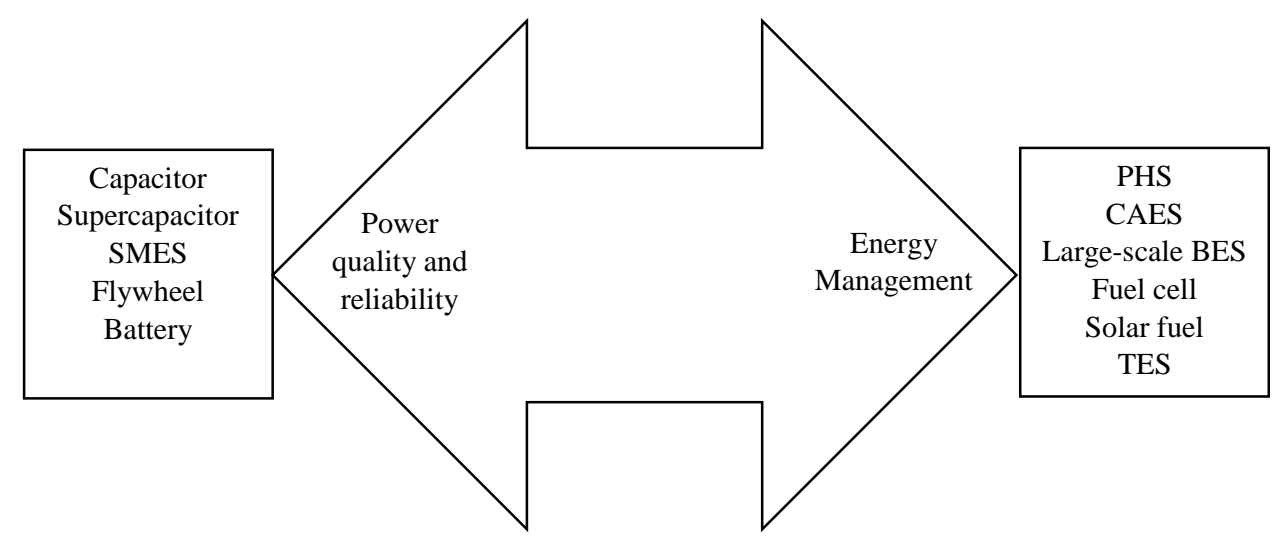

Figure 2.3: Classification of ESS technologies by functions [47].

storage devices that may be used as helpful metrics in selecting the most suitable storage systems to be adopted for a particular use [45,47]. For example, some grid management applications such as frequency regulation and load levelling, typically demands fast response times of the order of fractions of seconds which are suitable for flywheel and supercapacitor storage. Bulk power management on the other hand may require longer discharge duration of the order of hours with pumped-hydro and CAES offering these capabilities [48].

Aside from technical characteristics, capital cost of storage is another key factor for determining the viability and acceptance of storage deployment. The capital costs of the storage systems can be calculated in various ways, which include energy $\operatorname{cost}(\$ / \mathrm{kWh})$, power cost $(\$ / \mathrm{kW})$, and cost per cycle $\phi / \mathrm{kWh} /$ cycle. In terms of energy cost, CAES is the cheapest among the developed storage technologies for large-scale applications, with a capital cost of $\$ 2-50 / \mathrm{kWh}[45]$.

\subsubsection{Applications of Energy Storage Systems}

ESS provides electrical grid with numerous beneficial services and cost reduction, and companies are deploying storage technologies for various purposes. The conventional electricity network links the following: fuel/energy source, generation, transmission, distribution, and customer-side $[45,49]$, and ESS technologies being projected to play a significant role for all these in the near future. Large scale ESS enables modern electrical devices to operate significantly more efficiently, resulting in lower prices, less emission and more reliable power [16]. ESS can also be sited behind the meter at the customer's facility to serve 
various purposes, such as for managing peak load to save on electricity cost and for resilience. ESS is equally useful with the widespread deployment of RE resources which are intermittent in nature, producing energy when the sun is shining and the wind is blowing. By time shifting the energy from RE sources using ESS, clean technologies can supply reliable power throughout out the day [16, 19, 25, 28].

RE integration and energy time shift are only two of the many applications of storage, with ESS also enhancing power quality through frequency regulation, thus enabling companies to generate power when it is cheapest and most efficient, while providing an uninterrupted power source for critical infrastructure and services. Table 2.1 lists and describes the potential applications of energy storage at different levels of the power network value chain.

\subsection{Compressed Air Energy Storage (CAES)}

\subsubsection{CAES Overview}

CAES is a type of storage technology that uses off-peak electric energy to compress the air and store the compressed high-pressure air in a storage reservoir, which is then released during the peak-load periods to drive a turbine generator to produce electricity. CAES can use different reservoirs to store the compressed air, existing underground geological formations such as salt mine and hard-rock formations, porous rock and saline aquifers or depleted gas fields are ideally cost-effective storage mediums for large-scale CAES application [10]. Studies have shown that high-pressure air can also be stored in aboveground vessels or high-pressure piping (20-100 bars) [50], with this method eliminating the need for geological consideration and making the system easier to operate.

The schematic diagram of a CAES system is illustrated in Figure 2.4, and ideally consist of the following main components [10,51]: compressors; expanders; air reservoirs; combustor; motor/generator; controlling system; and other auxiliary equipment, such as fuel tanks, pipe connection and so on.

There are two different modes of operation for a CAES plant, namely compression and expansion and these modes can occur independently or simultaneously depending on the plant type. In the compression mode, off-peak low-cost electricity is used to run a chain of compressors which injects air into the reservoir at high pressure. The compressed air is stored at the temperature of the surrounding formation and at a certain pressure, which depends on the particular underground cavern chosen [51]. During the expansion stage, the 
Table 2.1: Potential Applications of Energy Storage Technologies [16]

\begin{tabular}{|c|c|c|}
\hline Category & Application & Description \\
\hline \multirow[t]{2}{*}{ Electric Supply } & Energy time-shift & $\begin{array}{l}\text { Store off-peak energy for resale at on-peak; store } \\
\text { energy that would otherwise be curtailed }\end{array}$ \\
\hline & Supply Capacity & $\begin{array}{l}\text { Provide peak generation capacity for electric power } \\
\text { system; defer investment in new capacity resources }\end{array}$ \\
\hline \multirow{5}{*}{ Ancillary Services } & Load Following & $\begin{array}{l}\text { Provide fast-responding resource to match genera- } \\
\text { tion to fluctuating load }\end{array}$ \\
\hline & $\begin{array}{l}\text { Frequency } \\
\text { Regulation }\end{array}$ & $\begin{array}{l}\text { Maintain the stability and accuracy of the system- } \\
\text { wide alternating current (AC) frequency within a } \\
\text { given control area }\end{array}$ \\
\hline & Reserve Capacity & $\begin{array}{l}\text { Provide reserve capacity should normal supply re- } \\
\text { sources unexpectedly become unavailable }\end{array}$ \\
\hline & Voltage Support & $\begin{array}{l}\text { Maintain voltage levels by injecting or absorbing } \\
\text { reactive power; service works best at distribution } \\
\text { level }\end{array}$ \\
\hline & Black Start & $\begin{array}{l}\text { Provide power up to re-energize the grid after a } \\
\text { grid-wide outage }\end{array}$ \\
\hline \multirow[t]{3}{*}{ Grid System } & Congestion Relief & $\begin{array}{l}\text { Avoid congestion-related cost and charges associ- } \\
\text { ated with inadequate transmission facilities }\end{array}$ \\
\hline & Upgrade deferral & $\begin{array}{l}\text { Defer or avoid need for transmission or distribution } \\
\text { system upgrades }\end{array}$ \\
\hline & $\begin{array}{l}\text { Substation } \\
\text { back-up power }\end{array}$ & $\begin{array}{l}\text { Supply back-up power to protection, communica- } \\
\text { tions and control equipment }\end{array}$ \\
\hline \multirow{5}{*}{ End User } & $\begin{array}{l}\text { Time-of-use } \\
\text { cost management }\end{array}$ & $\begin{array}{l}\text { Store off-peak energy to supply customer load dur- } \\
\text { ing the on-peak time-of-use rates }\end{array}$ \\
\hline & $\begin{array}{l}\text { Demand charge } \\
\text { management }\end{array}$ & $\begin{array}{l}\text { Discharge stored energy to reduce the customer's } \\
\text { peak power and peak demand charges }\end{array}$ \\
\hline & Power reliability & Use stored energy to ride through power outage \\
\hline & Power quality & $\begin{array}{l}\text { Protect on-site load from effects of short-term } \\
\text { power quality degradtion, such as voltage spikes, } \\
\text { dips or sags }\end{array}$ \\
\hline & $\begin{array}{l}\text { Renewable } \\
\text { self-consumption }\end{array}$ & $\begin{array}{l}\text { Increase self-consumption of an on-site renewable } \\
\text { generation }\end{array}$ \\
\hline \multirow[t]{2}{*}{ RE Integration } & Time-shift & $\begin{array}{l}\text { Store low-value energy generated by renwables at } \\
\text { off-peak times until it has a higher financial value }\end{array}$ \\
\hline & Capacity firming & $\begin{array}{l}\text { Mitigate variability by discharging stored energy } \\
\text { when the RE are not producing full power }\end{array}$ \\
\hline
\end{tabular}




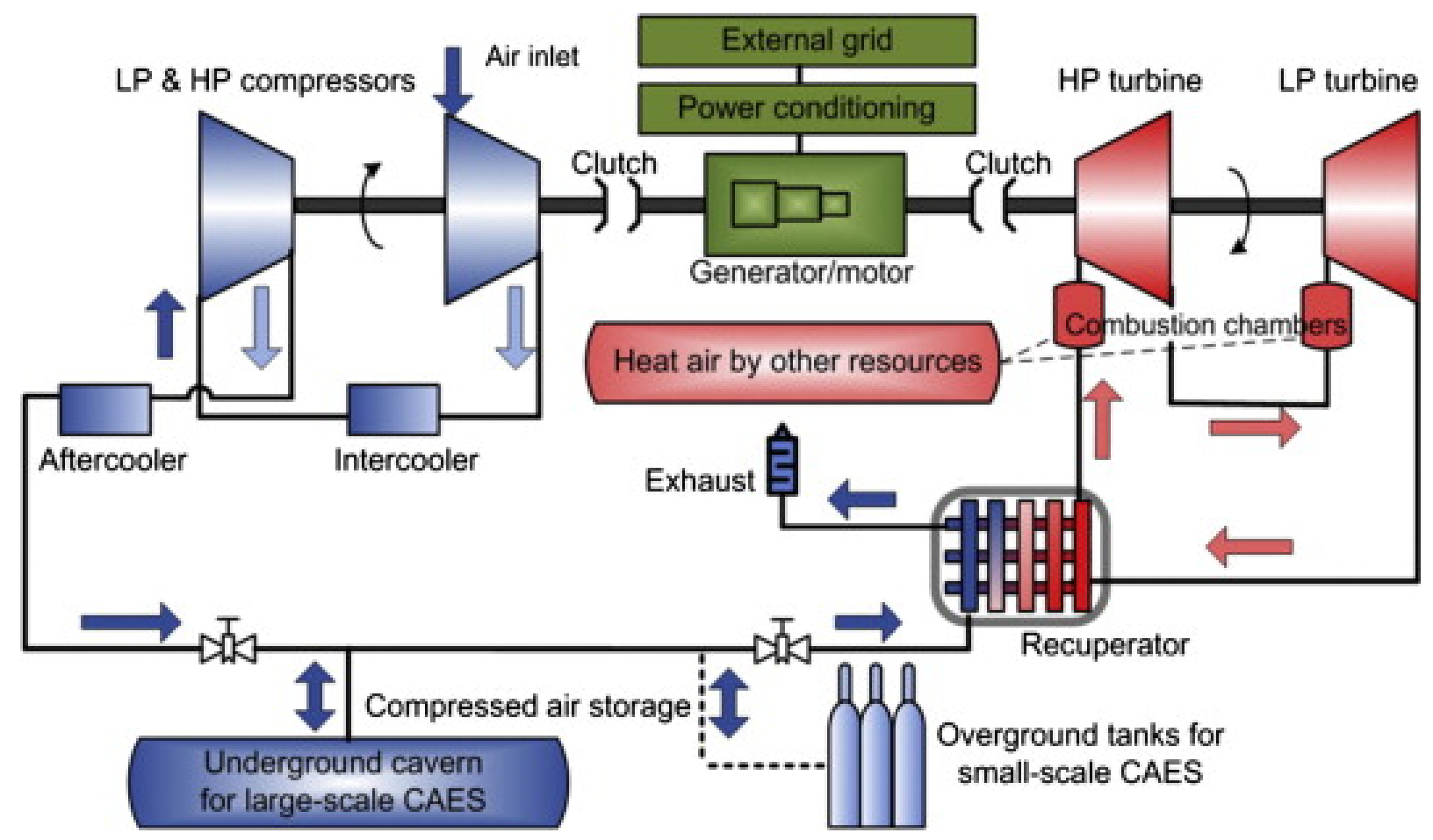

Figure 2.4: Basic components of a CAES system [47].

pressurized air is released from the reservoir and used to operate the gas turbine generator which produces electricity.

Based on the compression and air expansion heat management, CAES plant designs are categorized as shown in Figure 2.5. The compression heat is removed and dissipated during compression in D-CAES (often referred to as "conventional" or "first generation" CAES) and the air is heated during expansion [11,15,52]. Second-generation CAES is similar to the first-generation, except for a modified design that uses air injection techniques to increase efficiency to improve compression and/or expansion stages. In A-CAES, which is commonly referred to as third generation CAES, the heat recovered during compression is stored and reused during discharging $[52,53]$. Similar to A-CAES, Advanced A-CAES (AA-CAES) or fuelless CAES stores the heat of compression as well as the cooled high-pressure air and uses it to re-heat the air during the expansion process. Higher efficiencies and reduced carbon emissions are the key advantages of AA-CAES, as there is no fuel consumption required during generation. I-CAES is an evolving technology that tries to overcome some of traditional (diabatic or adiabatic) CAES limitations $[16,53]$. In I-CAES, the compression and expansion stages are carried out slowly to ensure that the air is maintained at an 




Figure 2.5: Classification of CAES based on heat management.

approximately constant temperature by exchanging heat with the environment. I-CAES design negates the need to store compression heat by certain secondary means (e.g. oil), and if perfect heat transfer to the environment can be achieved, the theoretical efficiency of isothermal CAES approaches 100 percent [10]; in practice, however, perfect thermodynamic cycles can not be achieved as some heat loss occurs [10].

There are currently two D-CAES plants in commercial operation: one in Huntorf, Germany, where a 290MW plant was built in 1978, and one in Alabama, USA, where a 110MW plant was built in 1991 [14,52]. Both were primarily built for black-start and peak shaving services. Many other demonstration CAES plants have been built or under construction at different places [17]; for example, a 1.5 MW SC-CAES demonstration project was designed by Macaoenergy (Bijie) Industrial Park Development Co. Ltd and Institute of Engineering Thermophysics of the Chinese Academy of Sciences in 2013, and the project has recorded 3000 hours of successful operation [52]. In November 2015, the Independent Electricity System Operator (IESO) selected NRStor to complete a 1.75 MW CAES project in a salt cavern in Goderich, Ontario [7], which will come into operation in 2019. 


\subsubsection{Small-Scale Compressed Air Energy Storage (SS-CAES)}

Most articles related to CAES focused on large-scale CAES plants for utility applications. Nevertheless, it is of great interest to develop SS-CAES close to energy demand for many end-use applications and other grid services where possible given the successful implementations of large-scale CAES. SS-CAES is in principle the same as large-scale CAES but on a lower level of output power and provides a solution to the restrictive site requirements of large-scale CAES, limiting thus far application to flexible artificial above ground storage vessels [6], and is more applicable to distribution systems.

\subsection{Electricity Pricing}

\subsubsection{Ontario Electricity Pricing}

Over the past decade, C\&I customers in Ontario have experienced a dramatic increase in electricity costs. According to [1], industrial electricity rates increased by 16 percent between 2013 and 2015 and, according to the data from a 2018 HydroQuébec survey [54] industrial customers in Ontario are now paying the highest electricity costs among all major Canadian cities and facing some of the highest costs across North America [1]. This rising electricity cost has placed large financial burden on Ontario's businesses and is threatening their competitiveness, particularly that of the manufacturing sector where electricity is a major input cost [1]. The issue of rising electricity costs in Ontario is directly linked to the policy choices of the provincial government, which includes aggressive promotion of renewable sources, poorly structured long-term contracts, and phasing out of coal [1]. The centrepiece of the Ontario's Green Energy and Green Economy Act of May 2009 was a feedin tariff program designed to encourage investments in renewable energy sources. With this program in place, the province began offering long-term guaranteed contracts at a fixed purchase price, significantly above market electricity prices, to generators with renewable sources. The fixed prices paid to these generators were recovered from two market-based components know as Hourly Ontario Energy Prices (HOEP), and the Global Adjustment (GA) [55]. The GA is a payment that makes up the difference between the wholesale price (HOEP) and the fixed contract rates in relation to the renewable sources feed-in tariff program, including the Ontario conservation costs, the expansion of gas capacity, and the nuclear power refurbishment programs [55]. The GA therefore has an inverse relationship with the HOEP and can be negative or positive depending on whether the HOEP for the generators is higher or lower than the guaranteed fixed rates. 


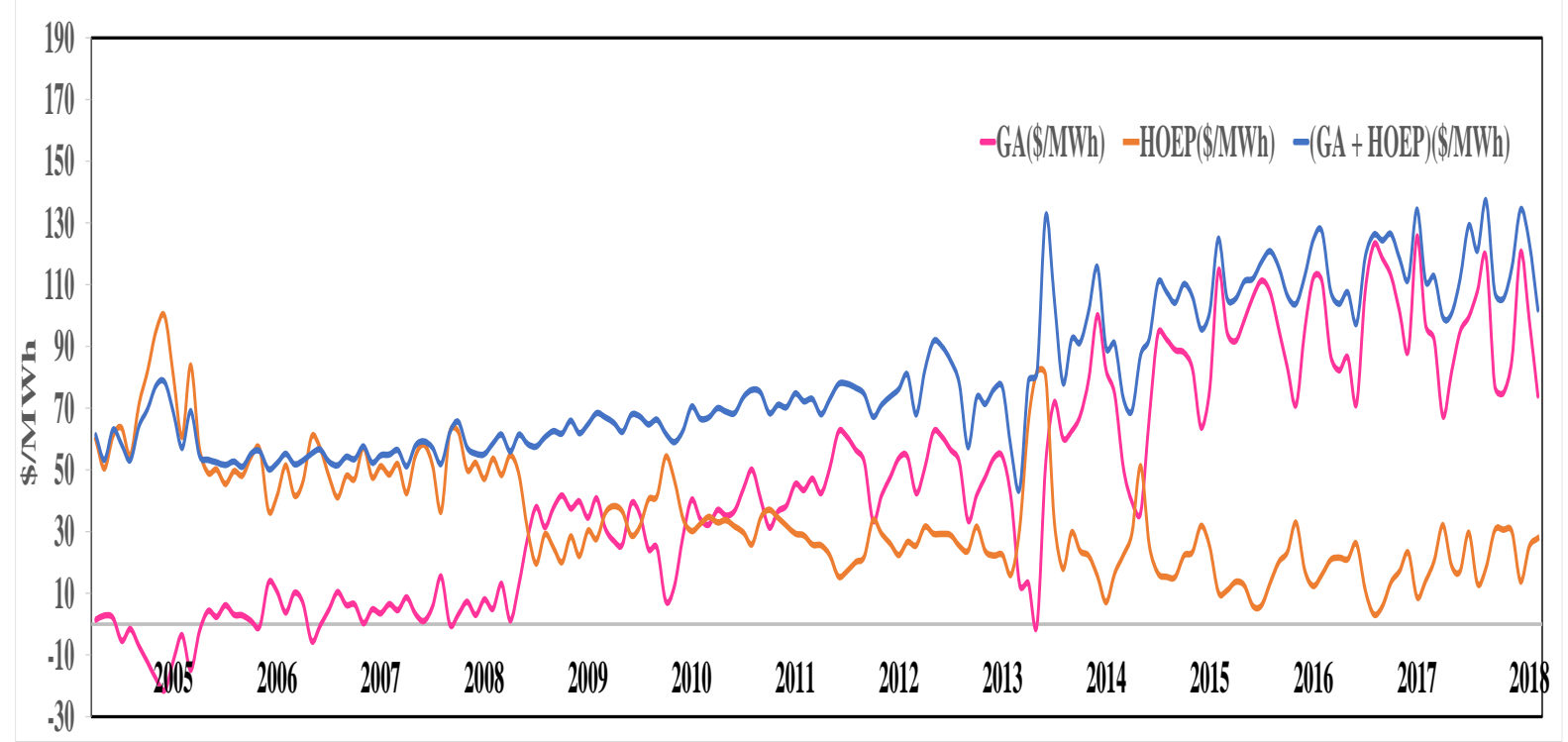

Figure 2.6: Real commodity cost (\$/MWh) $2005-2018$

The commodity portion is the largest of all components of electricity costs, accounting for 62 percent of the total electricity cost in 2014 [1]. As can be seen from Figure 2.6, the GA was a $\$ 20 / \mathrm{MWh}$ credit to electricity customers in 2005 , but, it rose dramatically since then to nearly $\$ 120 / \mathrm{MWh}$ in 2018 . It can be observed also that the significant increase in GA occurred while the HOEP decreased steadily over the same period, and becoming a relatively small fraction of the commodity cost. It is therefore clear that the primary driver of the rising electricity prices in Ontario is the GA and not the HOEP. The researchers in [1] pointed out that not all of the increase in the GA (and by extension, in the cost of electricity) is attributable to renewable sources, however, aggressive promotion of renewable energies under the Feed-in-Tariff program has significantly impacted the electricity price increase.

\subsubsection{Global Adjustment [3]}

The GA was established by the Ontario government in 2005 to cover the cost of providing adequate generating capacity and conservation programs in the province. The allocation of the GA cost between Class A (large industrial customers) and Class B (residential 
customers), are not even, rather they are charged different rates. Customers participating in the ICI program are referred to as Class A. Their share of the GA costs are assessed based on the percentage their consumption contributes to the top five system peaks during the predetermined base period (May 1 - April 30), and their percentage of total GA costs will be charged through the next billing period (July 1 - June 30). Figure 2.7 illustrates the ICI cycle.

\begin{tabular}{|c|c|c|c|c|c|c|c|c|c|c|c|c|}
\hline & Jan & Feb & Mar & Apr & May & Jun & Jul & Aug & Sep & Oct & Nov & Dec \\
\hline 2017 & & & & & \multicolumn{3}{|c|}{ BASE PERIOD } & & & & & \\
\hline 2018 & & & & & $\begin{array}{c}\text { OPT } \\
\text { IN/OU }\end{array}$ & & & & LIIN & ERI & & \\
\hline 2019 & & & & & & & & & & & & \\
\hline
\end{tabular}

Figure 2.7: Industrial Conservation Initiative Cycle [55]

Table 2.2: Calculating GA charge - Example

\begin{tabular}{|c|c|c|c|}
\hline Dates of $5 \mathrm{cp}$ & Hour Ending & $\begin{array}{l}\text { Coincident Demand of } \\
\text { the Customer (MW) }\end{array}$ & Ontario Demand (MW) \\
\hline July 29, 2015 & 17 & 10.063 & $23,023.71$ \\
\hline August 17, 2015 & 17 & 6.969 & $22,835.44$ \\
\hline July 27, 2015 & 17 & 9.484 & $22,892.24$ \\
\hline September 3, 2015 & 18 & 9.692 & $22,323.28$ \\
\hline \multirow[t]{2}{*}{ July 28,2015} & 14 & 6.278 & $22,860.23$ \\
\hline & Total & 42.486 & $113,934.90$ \\
\hline
\end{tabular}

At the end of the base period, a peak demand factor (PDF) of the customer is determined by dividing the sum of its load demand with the sum of Ontario's system-wide demand during the 5cp hours. The factor is used to multiply the total monthly Ontario GA cost to obtain the customer's monthly GA charge for the billing cycle. An illustration of the calculation of a GA charge for a hypothetical Class A customer is shown in Table 2.2. From Table 2.2, the PDF of the customer is obtained as: 


$$
P D F=\frac{42.486}{113934.900}=0.00037290
$$

For a system-wide GA cost of $\$ 1,208,819,619$ in July 2016, the customer's GA charge during July 2016 would be $0.00037290 \times \$ 1,208,819,619=\$ 450,768.8359$.

All electricity ratepayers in the province of Ontario pay the GA, even if it is not stated on the bill. For the residential and small commercial customers, the GA is embedded in their Time-of-use and Tiered Tariffs which is determined by the Ontario Energy Board [3].

\subsection{Summary}

Background studies on ESS, their components, classification, applications and benefits were presented in this chapter. Ontario electricity rate structure was analyzed and discussions on GA, which constitutes the major driver for the rising cost of electricity in Ontario were presented. An overview of CAES system, detailing the subsystems and their working principles was presented. 


\section{Chapter 3}

\section{Optimal Operation of SS-CAES Systems for Customer Load Management}

This chapter examines the impact of a SS-CAES facility installed behind-the-meter of an industrial customer. In particular, its role in the load management of the facility vis-a-vis its contribution to the customer's electricity cost reduction is analyzed.

\subsection{Framework}

The objective of the proposed SS-CAES system operation model is to minimize the electricity cost and the CAES system operation cost incurred by the industrial customer. Thus an optimization problem is formulated considering a given capacity of SS-CAES, and the decision variables are the charging/discharging decisions of the SS-CAES and energy purchase/consumption schedules of the customer, over a given time horizon. The flowchart in Figure 3.1 summarizes the modeling framework to achieve the load reduction for electricity cost saving in an industrial facility using behind-the-meter SS-CAES.

The total base-case cost of the industrial customer comprises the energy cost (EnC) and the GA charge (GAC), which is estimated using the customer's load data, the HOEP and Ontario's monthly GA obtained from IESO website [3]. It is considered that CAES is deployed to shave the demand during the $5 \mathrm{cp}$ hours and also to reduce the hourly energy drawn from the grid. Different sets of power and energy ratings of the SS-CAES are 


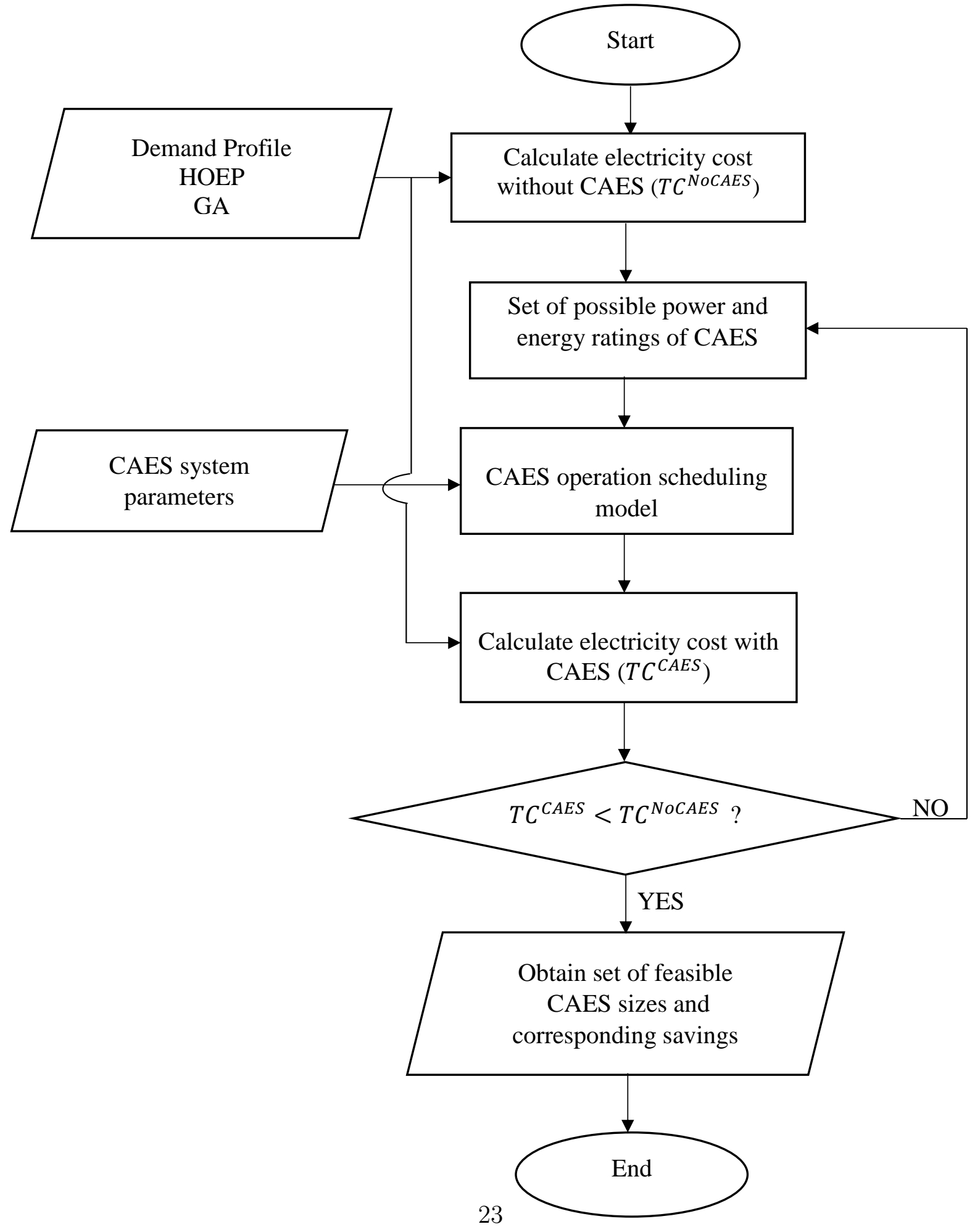

Figure 3.1: Proposed optimization process flow diagram. 
considered. A pair of power and energy rating of SS-CAES is considered a feasible set if the total cost of the industrial customer with CAES $\left(T C^{C A E S}\right)$ is lower than its total cost without CAES $\left(T C^{N o C A E S}\right)$. The obtained savings for each set of feasible SS-CAES ratings are recorded for economic evaluation and sensitivity analysis.

\subsection{Mathematical Model}

\subsubsection{Objective Function}

This section presents the objective function of a Class A customer without and with a CAES plant installed in its facility to reduce its GAC, EnC and CAES operation and maintenance O\&M cost $(S V O M C$ and $S F O M C)$ and these constitute the total costs (TC) of the facility.

The total cost of the customer without the CAES installation is given as follows:

$$
T C^{N o C A E S}=E n C^{N o C A E S}+G A C^{N o C A E S}
$$

where the $E n C^{N o C A E S}$ is the cost of energy consumed by the customer at each time interval at the corresponding energy price and is given as follows:

$$
E n C^{N o C A E S}=\sum_{d=1}^{365} \sum_{h=1}^{24} P D_{d, h} E p_{d, h}
$$

The component $G A C^{N o C A E S}$ is determined from the customer's contribution to the top five Ontario peak load hours, and can be expressed as:

$$
G A C^{N o C A E S}=\sum_{5 c p=1}^{5} \frac{P D_{d, h}}{O N D_{d, h}} \sum_{m=1}^{12} T O M G A C_{m}
$$

In (3.2) and (3.3), $P D_{d, h}$ is the power demand of the customer at hour $h$ of day $d$ to meet its energy demand; $E p_{d, h}$ is the corresponding hourly energy price, which is assumed same as the HOEP; $O N D_{d, h}$ represents the total Ontario system wide demand at the 5cp hours; and TOMGAC $C_{m}$ is the monthly Ontario-wide total GA costs and it varies from month to month depending on whether the HOEP increased or decreased, as these two are inversely related [3]. The first term of (3.3) denotes the customer's PDF obtained from its load contribution to the Ontario 5cp during the 12 month base period (May 1 to April 30) and 
is applied in the billing period (July 1 to June 30 ) to determine the customer's monthly GAC.

To determine the impact of deploying CAES on the total annual electricity bill savings, the total annual cost of the industrial customer can be defined as:

$$
T C^{C A E S}=E n C^{C A E S}+G A C^{C A E S}+S V O M C+S F O M C
$$

where:

$$
\begin{gathered}
E n C^{C A E S}=\sum_{d=1}^{365} \sum_{h=1}^{24} \operatorname{Pgrid}_{d, h} E p_{d, h} \\
G A C^{C A E S}=\sum_{5 c p=1}^{5} \frac{\operatorname{Pgrid}_{d, h}}{O N D_{d, h}} \sum_{m=1}^{12} T O M G A C_{m} \\
S V O M C=\sum_{d=1}^{365} \sum_{h=1}^{24}\left(V O M C_{c o m p} P_{d, h}^{C h}+V O M C_{e x p} P_{d, h}^{D C h}\right) \\
S F O M C=C A P E X(F O M C)
\end{gathered}
$$

In (3.5) and (3.6), Pgrid $_{d, h}$ is the power drawn by the customer from the grid to meet its energy demand and charge the CAES system when necessary, since the CAES facility is behind the customer's meter, as illustrated in Figure 3.2.

The SVOMC component comprises only the variable O\&M cost during charging and discharging operation of the CAES. Another important cost metric considered for the economic analysis of a CAES project is the annual fixed O\&M cost per year $(S F O M C)$. According to consultations with industry partners, a good general starting point for the $(F O M C)$ is $1-1.5 \%$ of the capital cost $(C A P E X)$. For the current work, the FOMC of the CAES project is considered to be $1.5 \%$ of the CAPEX.

The objective of the model is to minimize the total annual electricity charges and CAES operating costs while satisfying the facility's constraints. The is formulated as an optimization problem, and the energy output of the CAES unit for each time interval are the decision variables, as discussed next. The total annual cost reduction of the customer from using CAES to reduce demand from the grid are recorded as savings and are determined as follows:

$$
\text { Savings }=T C^{N o C A E S}-T C^{C A E S}
$$




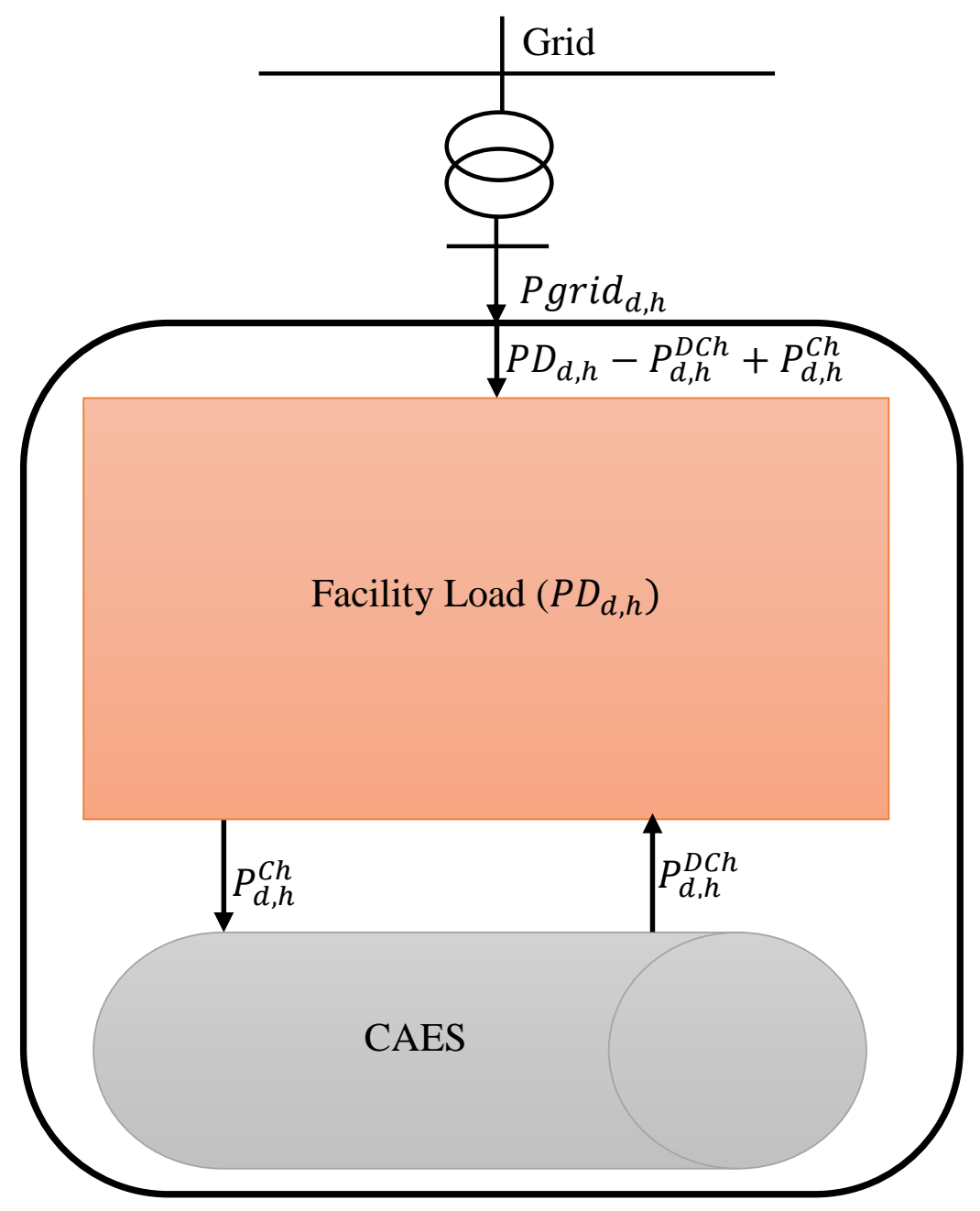

Figure 3.2: Schematic diagram of the facility load and CAES.

\subsubsection{Model Constraints}

\subsubsection{Demand-Supply Balance}

At each time interval, the customer's load is met by the power from the grid supply and the power discharged from the CAES, as follows:

$$
\text { Pgrid }_{d, h}-P_{d, h}^{C h}+P_{d, h}^{D C h}=P D_{d, h} \quad \forall d, h
$$




$$
\text { Pgrid }_{d, h} \leq \text { Pgrid }^{\text {max }} \quad \forall d, h
$$

Note that when the SS-CAES system operates in charging mode, it appears as an additional load of the customer. Equation (3.11) represents the grid supply constraint, which is typically governed by the substation transformer capacity.

\subsubsection{SS-CAES Capacity Constraints}

The operation of the SS-CAES facility is governed by the operation of its input and output systems and the storage reservoir.

\section{CAES Power Capacity}

The charging power drawn by the SS-CAES is limited by the compressor minimum and maximum limits (in MW) as follows:

$$
P_{\text {comp }}^{m i n} U_{d, h}^{C h} \leq P_{d, h}^{C h} \leq P_{c o m p}^{\max } \quad \forall d, h
$$

Similarly, the power discharged by the CAES facility is constrained by the minimum and maximum limits of the expander as follows:

$$
P_{e x p}^{\min } U_{d, h}^{D C h} \leq P_{d, h}^{D C h} \leq P_{e x p}^{\max } \quad \forall d, h
$$

\section{CAES Energy Capacity}

The energy stored or discharged at each time interval is limited by the allowable state-ofcharge (SOC) limits of the CAES, as follows:

$$
E^{\min } \leq E_{d, h} \leq E^{\max } \quad \forall d, h
$$

where $E_{d, h}^{\min }$ is set to zero, which is different than a BES, while $E_{d, h}^{\max }$ is the maximum energy capacity of the cavern. The initial SOC of the CAES is assumed to be $50 \%$ of the installed CAES energy capacity, i.e.:

$$
E_{d, h}=0.5 E^{\max } \quad d=1, h=1
$$




\section{CAES Energy Balance}

The amount of compressed air in the storage is considered in terms of the electrical output energy (i.e., the energy is stored as MWh of electricity rather than compressed air volume and pressure). Of the amount of electricity being drawn in the compression mode, only a fraction of it, depending on the efficiency of the compressor $\left(\eta_{\text {comp }}\right)$, is stored as mechanical energy. Figure 3.3 illustrates the energy balance of the CAES cavern, where the energy released from the cavern is a fraction of the efficiency of the expander $\left(\eta_{\text {exp }}\right)$. Assuming that the energy loss in the cavern is negligible, the equivalent amount of the energy stored in the CAES unit at the end of each time interval is given as follows:

$$
E_{d, h}=E_{d, h-1}+P_{d, h}^{C h} \eta_{c o m p}-\frac{P_{d, h}^{D C h}}{\eta_{\text {exp }}} \quad \forall d, h
$$

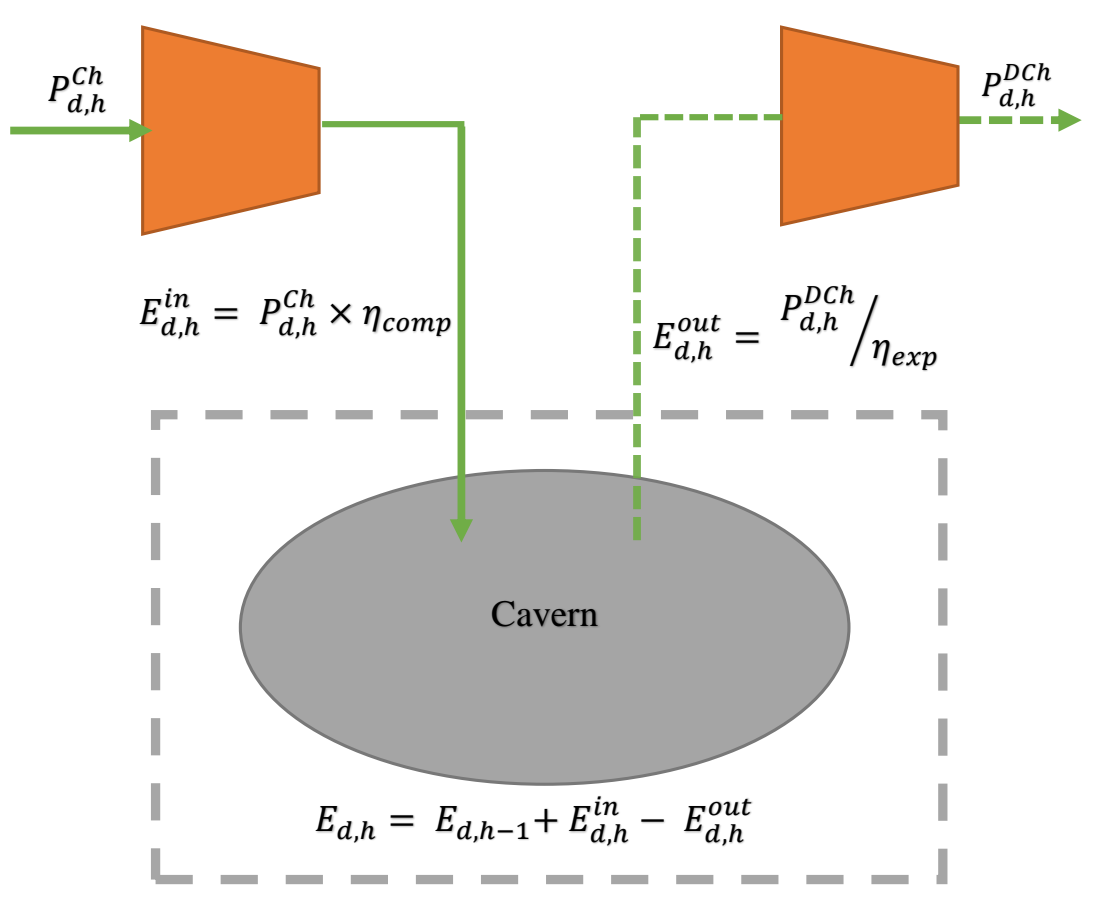

Figure 3.3: Energy balance of the CAES reservoir [53] 


\section{Coordination of Charging and Discharging}

There is a need to ensure that the charging and discharging of the CAES system does not occur simultaneously, except when the design of the CAES plant allows the compressor and the generator operations to be decoupled. Accordingly, it is assumed here that:

$$
U_{d, h}^{C h}+U_{d, h}^{D C h}=1 \quad \forall d, h
$$

\section{Annual Maintenance Provision}

The CAES should be scheduled for annual maintenance, and thus, a downtime constraint is imposed on the CAES unit to account for the scheduled maintenance as follows:

$$
\sum_{d=1}^{365} \sum_{h=1}^{24}\left(U_{d, h}^{C h}+U_{d, h}^{D C h}\right) \leq 8760(1-M D T)
$$

where $M D T$ is the minimum downtime in percentage of hours in a year.

The proposed model given by (3.1) to (3.8) and (3.10) to (3.18) is an MILP problem and is implemented in the General Algebraic Modeling System (GAMS) [56], a high-level modeling system for solving mathematical programming problems. The CPLEX 12.5 solver included in GAMS is used to solve the proposed MILP optimization problem.

\subsection{Results and Analysis}

The aforementioned model is applied to a load profile of a real Class A customer in Ontario, to determine the possible cost reduction resulting from deploying an SS-CAES system at the customer's facility to reduce the load demand and energy drawn from the grid. As discussed in the previous chapter, the reduction in the facility's demand using CAES will not change its GAC for the current month; for example, a load demand reduction in June of 2017 will reflect in the GAC for June 2019. Therefore, to capture the overall impacts of CAES in details, the electricity charges for the complete ICI cycle is considered. Thus, in the base period, the PDF of the customer is determined and applied in the adjustment period to determine the monthly GAC of the customer. 


\subsubsection{Input Data}

\subsubsection{Electricity Prices}

The following data made available by IESO [3] are used for the present studies:

- HOEP from May 1, 2015 to June 30, 2017

- Monthly GA charges from July 2015 to June 2017

Figure 3.4 presents a sample of a one-week HOEP in Ontario. The wholesale energy price takes negative values in some hours, which implies that a CAES can harness these low-cost energy for use at high-cost peak hours.

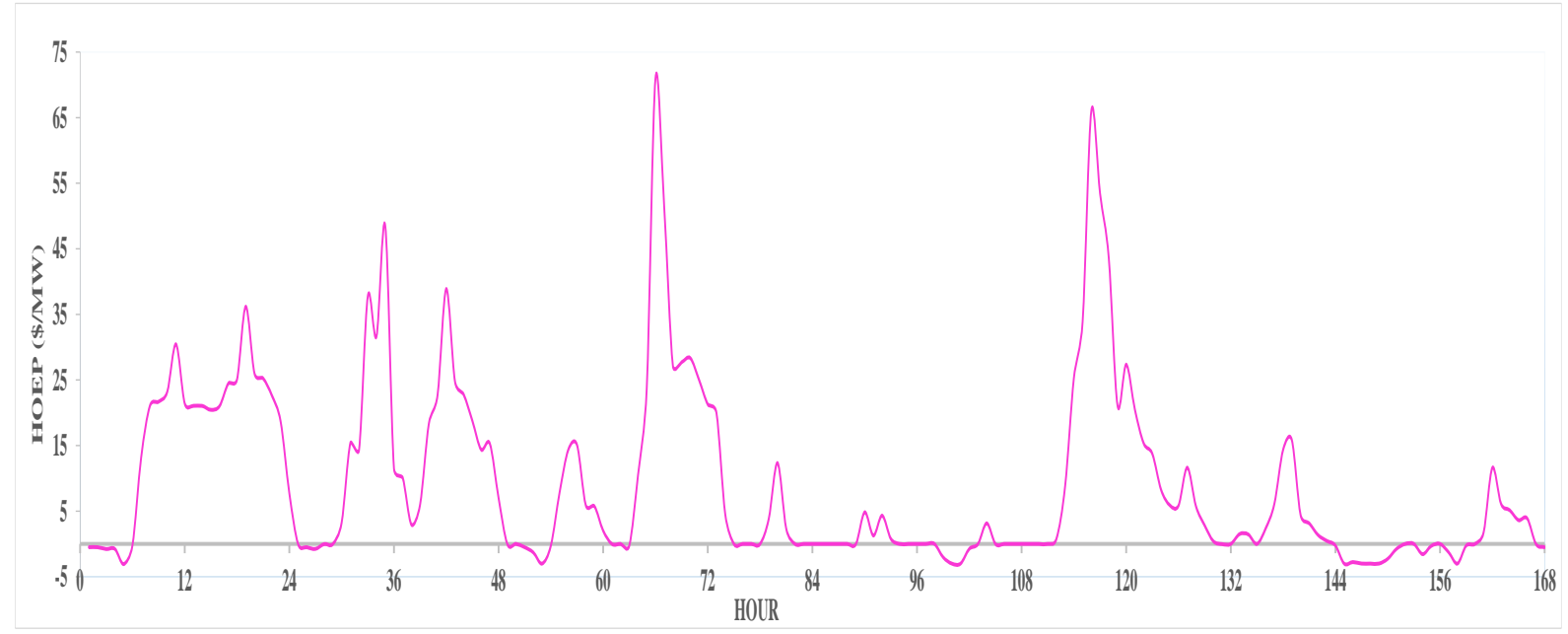

Figure 3.4: Sample of one week HOEP.

The GAC for the base period is fixed and EnC is obtained using the HOEP and the energy demand of the customer. The CAES is dispatched to reduce the facility's demand during the $5 \mathrm{cp}$ hours, and the power demand at these hours are used to determine the customer's PDF. In the adjustment or billing cycle, the PDF is used to multiply the $T O M G A C_{m}$ to obtain the monthly GAC of the customer as a result of CAES deployment. Equation (3.4) which captures the total annual electricity cost of the customer, is minimized in the optimization model. 


\subsubsection{Demand Profiles}

The typical daily load profile of a class A customer is shown in Figure 3.5, while Figure 3.6 shows annual load duration curve of the same facility. The peak demand of the customer is $14.27 \mathrm{MW}$, as can be seen from Figure 3.6; however, this peak demand occurred for less than $2 \%$ of the hours in the year. Furthermore, note that only about $10 \%$ of the hours, the facility demand was more than $11 \mathrm{MW}$. This observation is vital to avoid over sizing the CAES, which will increase the investment cost.

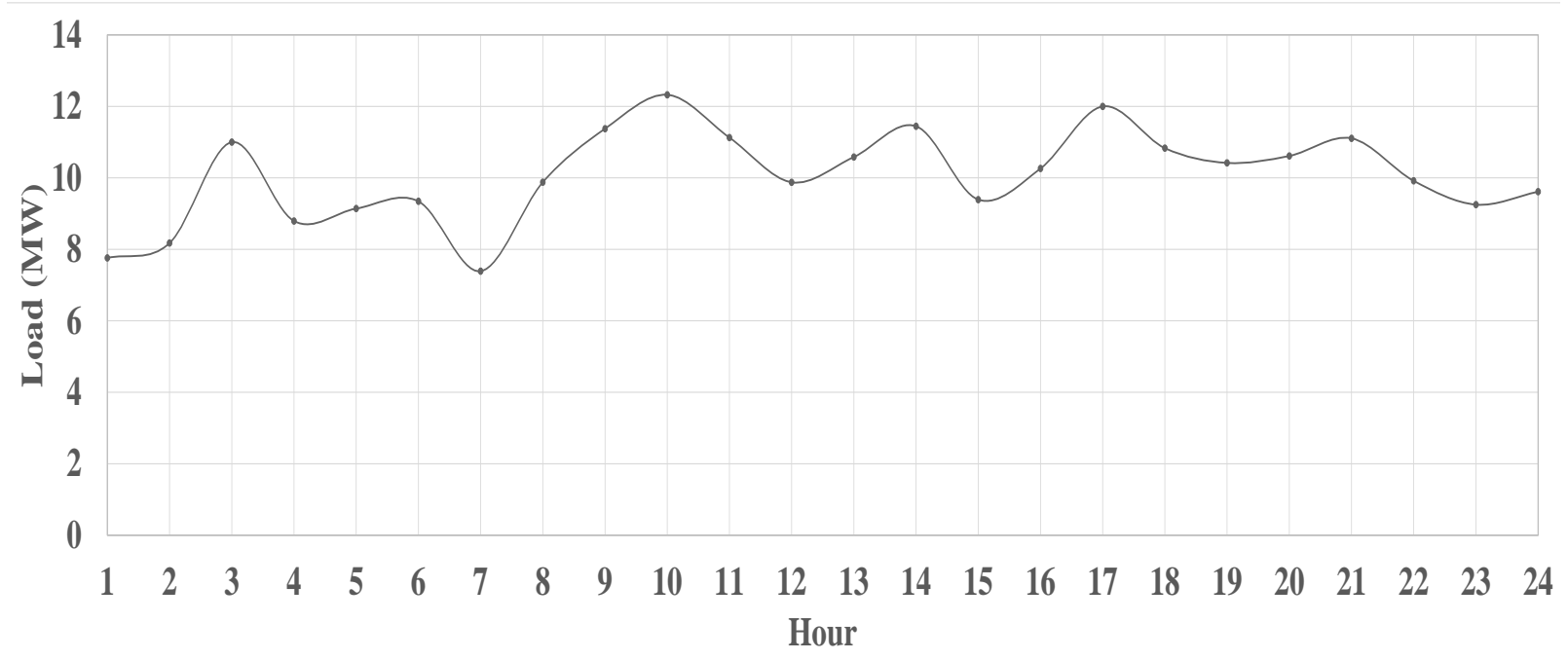

Figure 3.5: Demand profile the industrial customer.

Figure 3.7 captures the daily load profile of the facility on the 5cp days of the base period (May 2015 - April 2016), and the bar charts denotes the percentage of occurrence of $5 \mathrm{cp}$ at each hour from 2011 to 2017 . Observe that approximately $70 \%$ of the time, the system peak occurred at hours 16 or 17, and the customer's load also peaked at these hours. Hence, it can be inferred that these are very critical operation hours for the facility and load curtailing may not be preferred; thus, ESS is the most suitable strategy to manage their load under this circumstance.

\subsubsection{SS-CAES Parameters and Assumptions}

Table 3.1 presents the parameter of the SS-CAES system used for this study. Different sizes of CAES were considered at an increment of 1 MW up to 10MW, based on the facility's 


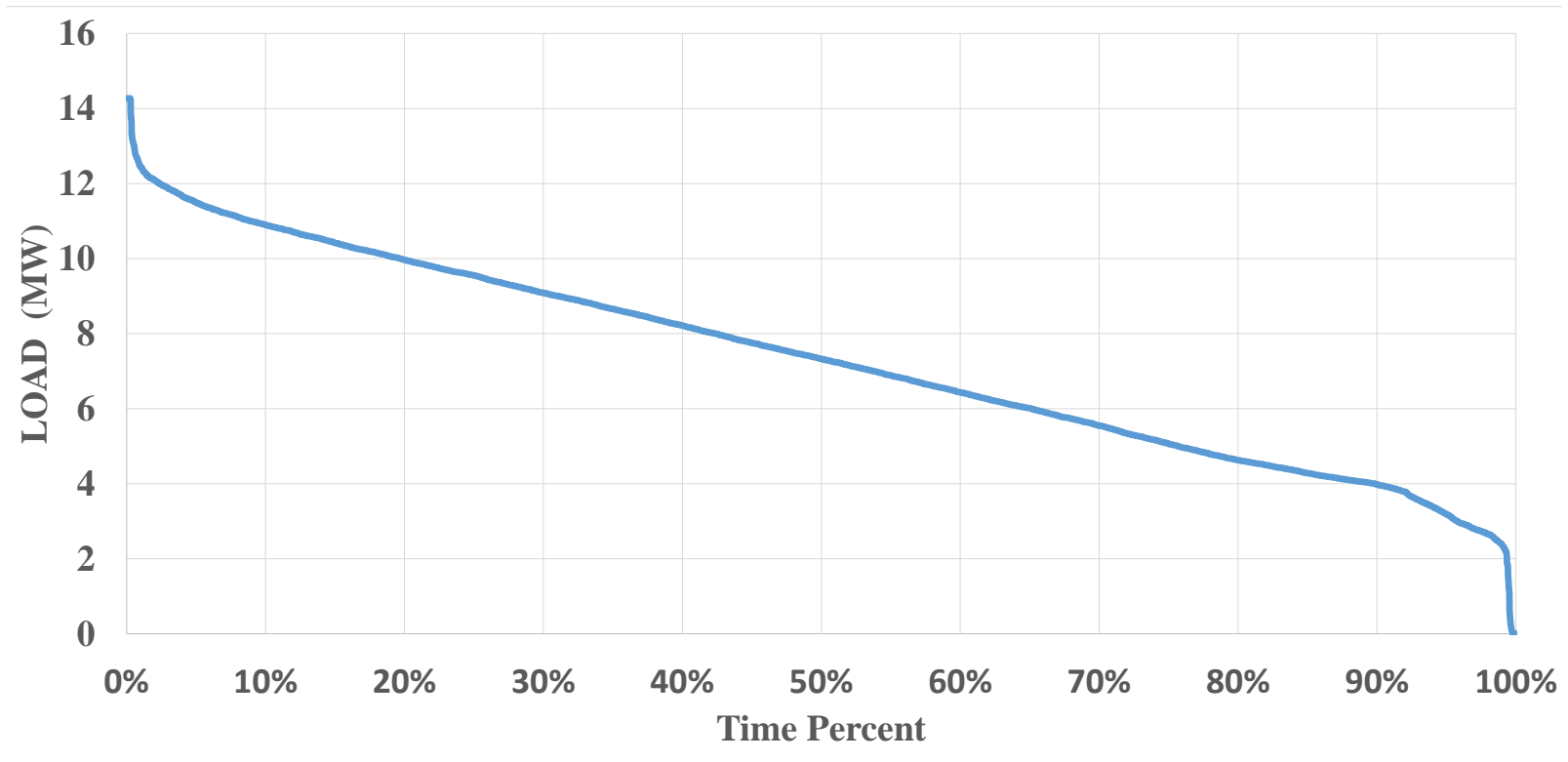

Figure 3.6: Annual load duration curve of the industrial customer.

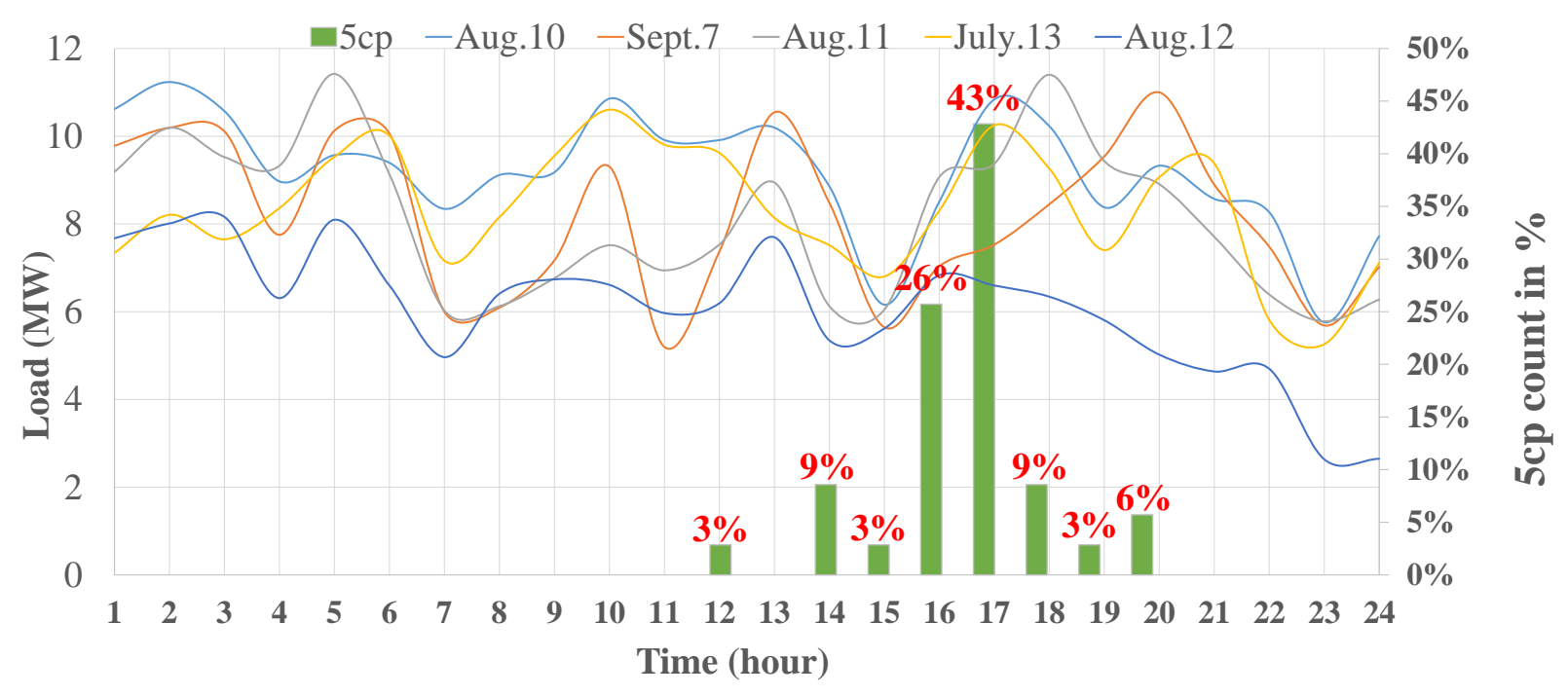

Figure 3.7: Customer's load profile at the 5cp hours between May 2016 to April 2017 and 5cp \% occurrence between 2011 and 2017. 
Table 3.1: Parameters of the CAES System $[7,57]$

\begin{tabular}{lll}
\hline Parameters & Values & Units \\
\hline$P_{\text {exp }}^{\max }$ & 1 to 10 & $\mathrm{MW}$ \\
$P_{\text {comp }}^{\max }$ & 1 to 10 & $\mathrm{MW}$ \\
$P_{\text {exp }}^{\min }$ & $20 \%$ of $P_{\text {exp }}^{\max }$ & $\mathrm{MW}$ \\
$P_{\text {comp }}^{\min }$ & $20 \%$ of $P_{\text {comp }}^{\max }$ & $\mathrm{MW}$ \\
$C A P E X$ & 1500 to 3000 & $\$ / \mathrm{kW}$ \\
$F O M C$ & $5 \%$ of $C A P E X$ & $\$ / \mathrm{kW}-\mathrm{year}$ \\
$V O M C_{\text {comp }}$ & 7.06328 & $\$ / \mathrm{MWh}$ \\
$V O M C_{\text {exp }}$ & 7.06328 & $\$ / \mathrm{MWh}$ \\
$E^{\text {max }}$ & 2 to 20 & MWh \\
$E^{\text {min }}$ & 0 & MWh \\
MDT & $5 \%$ & of total hours in a year \\
$\eta_{\text {comp }}$ & 0.8 & - \\
$\eta_{\text {exp }}$ & 0.8 & - \\
\hline
\end{tabular}

peak load, and for various discharge hours, depending on the power capacity to study the impact of energy capacity. The 5cp days and hours are known apriori and the customer's load is considered fixed for the planning horizon. For the sake of simplicity, the compressor power and generator power ratings are the same. The O\&M cost is taken from [57], and the efficiency of the CAES plant are obtained from [7].

Other assumptions made in the present research work are: 
- The industrial customer has empty wells/caverns that can be re-purposed for air storage.

- The technology considered is the AA-CAES (fuel-free).

- The unit capital cost of the CAES facility is in $\$ / \mathrm{kW}$.

- Although the CAES facility can be used to provide multiple ancillary services to increase the investor's revenue, in the current work, only load management services are considered.

- The thermodynamic characteristics of AA-CAES technology were not explicitly included in the model.

Table 3.2: Cost Reduction for Different CAES Sizes

\begin{tabular}{lllllll}
\hline CAES Sizes & $\begin{array}{l}\text { GAC } \\
(\$)\end{array}$ & $\begin{array}{l}E n C \\
(\$)\end{array}$ & $\begin{array}{l}\text { SVOMC } \\
(\$)\end{array}$ & $\begin{array}{l}\text { SFOMC } \\
(\$)\end{array}$ & $\begin{array}{l}\text { TC } \\
(\$)\end{array}$ & $\begin{array}{l}\text { Savings } \\
(\$)\end{array}$ \\
\hline \hline 0 & $6,671,682$ & $1,053,483$ & 0 & 0 & $7,730,165$ & 0 \\
\hline 1MW/2MWh & $6,671,682$ & $1,058,483$ & 0 & 0 & $7,730,165$ & 0 \\
\hline 2MW/4MWh & $5,662,064$ & 989,084 & 18,274 & 90,000 & $6,669,424$ & 970,743 \\
\hline 3MW/6MWh & $5,157,255$ & 954,426 & 27,380 & 106,875 & $6,245,937$ & $1,484,228$ \\
\hline 4MW/8MWh & $4,652,446$ & 920,447 & 36,354 & 123,750 & $5,732,999$ & $1,997,166$ \\
\hline 5MW/10MWh & $4,147,637$ & 888,610 & 45,125 & 140,625 & $5,221,998$ & $2,508,166$ \\
\hline 6MW/12MWh & $3,642,828$ & 859,172 & 53,561 & 157,500 & $4,713,062$ & $3,017,103$ \\
\hline 7MW/14MWh & $3,138,019$ & 832,923 & 61,594 & 174,375 & $4,206,912$ & $3,523,252$ \\
\hline 8MW/16MWh & $2,633,210$ & 809,065 & 69,137 & 191,250 & $3,702,663$ & $4,027,501$ \\
\hline 9MW/18MWh & 2128401 & 788,106 & 76,350 & 208,125 & $3,200,983$ & $4,529,182$ \\
\hline 10MW/20MWh & $1,623,592$ & 769,301 & 83,353 & 225,000 & $2,701,246$ & $5,028,919$ \\
\hline
\end{tabular}




\subsubsection{Results}

The results shown in Table 3.2 indicates that the Class A customer could save up to a minimum of $\$ 970,742$ in electricity cost per year for a CAES size of $2 \mathrm{MW} / 4 \mathrm{MWh}$, with increasing savings as the size increases. In Figure 3.8, a 1-week dispatch of the CAES operation model is illustrated. Note that the CAES system is able to respond to changing electricity prices, charging at low prices and discharging during high price hours.



Figure 3.8: One week operation of the CAES dispatch model.

To further understand the impact of the energy capacity of the CAES plant on the cost reduction, a fixed discharge power capacity is considered while increasing the energy capacity, and the results are shown in Figure 3.9. Observe that the energy capacity does not play a significant role in the cost savings; for example, doubling the energy capacity of the CAES, only increased the savings by $1.13 \%$ annually. This is because the cost savings are primarily dependent on the GAC reduction, which depends on th CAES power discharge rating. 


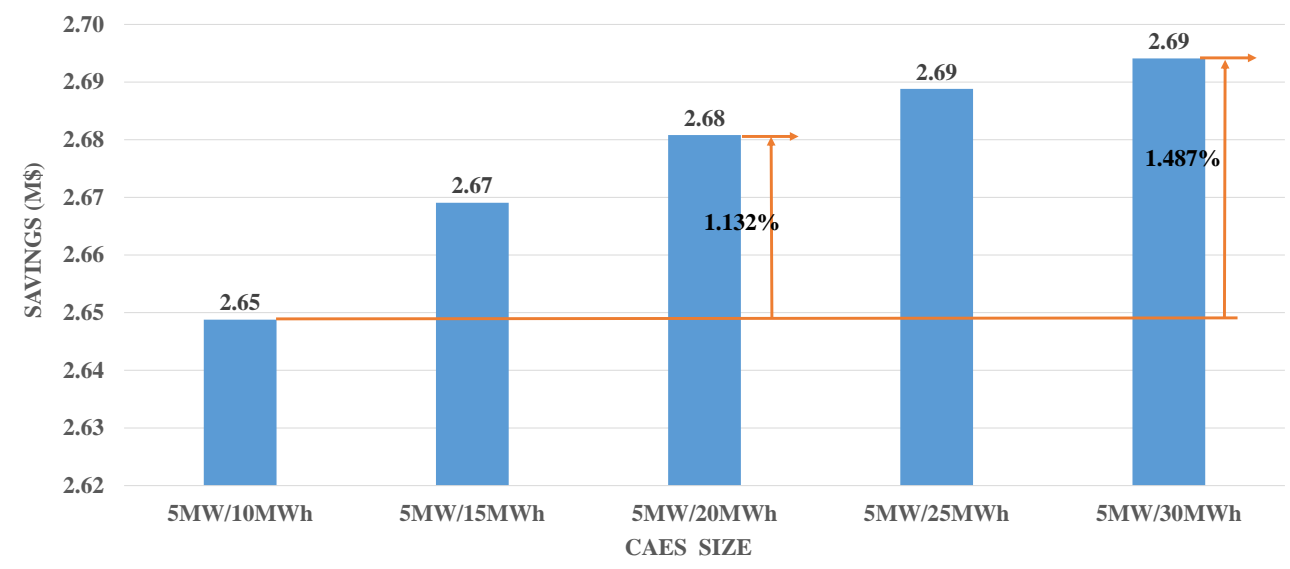

Figure 3.9: Impact of CAES energy capacity on cost reduction.

\subsection{Summary}

In this chapter, an operational model of CAES was presented with the objective of minimizing customers' electricity costs. The resulting MILP model was solved in GAMS using different sizes of CAES. The results showed that CAES sited behind-the-meter is a viable option for a real customer participating in the ICI program to reduce its electricity costs; however, determining the feasible sizes requires an economic analysis taking into account the capital cost to determine if the investment is worth it, as discussed in the next chapter. The cost reduction is achieved by reducing the demand charges, which are dependent on the GA, and the energy costs, which are dependent on the amount of power drawn from the grid.

Note that the operation model developed in this work is generic to energy storage systems operation, and can be used to study how other energy storage technologies like BES compares with SS-CAES in the context of customer's load management. 


\section{Chapter 4}

\section{Economic Analysis of CAES Facility}

This chapter examines the economic feasibility and risks over the long-term of a SS-CAES plant installed at a customer's facility for load management applications. Different CAES sizes, electricity prices, CAES unit costs, and life cycle times are considered for sensitivity analysis to evaluate how the revenue of the investor would be impacted by the changes.

\subsection{Economic Analysis}

The annual savings in electricity cost accrued from the installation of an SS-CAES system to shave the facility's load demand is given as follows:

$$
S_{y}=T C_{y}^{N o C A E S}-T C_{y}^{C A E S}
$$

where $S_{y}$ is the annual savings of the facility. The internal rate of return $(I R R)$ for the investment in CAES system can be obtained by solving the following equation [58]:

$$
\sum_{y=1}^{N} \frac{S_{y}}{(1+I R R)^{N}}-C A P E X=0
$$

where $N$ is the CAES project life in years and $C A P E X$ is the initial capital cost of the SS-CAES system.

In practice, when planning investment projects, companies often set a minimum acceptable rate of return (MARR) to determine the minimum acceptable IRR of the investment 
to be worthwhile. Technically, any project with an IRR that exceeds the MARR is deemed a profitable one [58]. MARR vary from project to project and depends on different factors such as project risk, investment opportunities, and limits on available capital [58]. A 10\% MARR is considered for low risk investments [59]; therefore, a moderate $14 \% \mathrm{MARR}$ is considered for the project analyzed in this work.

\subsubsection{Basic Analysis}

To gain an insight into the economic value of deploying behind-the-meter SS-CAES to manage the load of a Class A customer in Ontario, a simplified basic economic analysis is performed first. Thus, as noted in the previous chapter, the customer's maximum demand is 14.27 MW. However, from their detailed metered data, only $3 \%$ of the time did their load exceed $12 \mathrm{MW}$ in a year, which is also validated by their average monthly peak demands of $12.49 \mathrm{MW}$, as per Table 4.1. In view of this, to avoid oversizing the CAES unit, the customer's demand for the 5cp hours is assumed fixed at $12 \mathrm{MW}$ for a basic economic analysis. Hence, for different targeted percentage load reduction, appropriate sizes of CAES facility can be considered as follows:

- Power rating varying from $2 \mathrm{MW}$ to $10 \mathrm{MW}$, with $1 \mathrm{MW}$ step size.

- Energy rating correspondingly varying from 4 MWh to 20 MWh, with 2 MWh step size.

The capital cost of the CAES project varies depending on scale, mode of storage medium and location [7]. The range of unit capital costs considered in this research is adopted from Hydrostor's AA-CAES project as 1,500 to 3,000 \$/kW [7], which reflects all costs of a CAES system. Hence, the upper value of the cost is considered here for the lower range CAES capacity (2 MW), and the lower cost value for the higher CAES size (10 MW). Assuming a linear relationship between $C A P E X$ and the CAES unit size, the intermediate costs can be estimated as shown in Figure 4.1 and tabulated in Table 4.2.

In this basic analysis, only the GAC is considered, since this is the major driver of behind-the-meter SS-CAES applications; thus, the energy cost are not considered here. Therefore, based on above discussed input data, the IRR for different CAES sizes and project life times can be evaluated, yielding the results depicted in Figure 4.2.

Note that CAES systems with higher power ratings, even for shorter project life cycles, yield a high IRR. Observe that, a nominal 2 MW CAES system with a project life of 
Table 4.1: Monthly Peak Demand of the Industrial Customer

\begin{tabular}{cc}
\hline Month & Peak Demand(MW) \\
\hline May-16 & 11.266 \\
Jun-16 & 11.527 \\
Jul-16 & 12.112 \\
Aug-16 & 11.914 \\
Sep-16 & 12.379 \\
Oct-16 & 12.698 \\
Nov-16 & 13.094 \\
Dec-16 & 12.238 \\
Jan-17 & 13.132 \\
Feb-17 & 14.321 \\
Mar-17 & 12.208 \\
Apr-17 & 12.988 \\
\hline Average & $\mathbf{1 2 . 4 9 0}$ \\
\hline
\end{tabular}

Table 4.2: CAES CAPEX Estimated

\begin{tabular}{cc}
\hline CAES SIZE (MW) & CAPEX (\$) \\
\hline 2 & $6,000,000$ \\
3 & $7,125,000$ \\
4 & $8,250,000$ \\
5 & $9,375,000$ \\
6 & $10,500,000$ \\
7 & $11,625,000$ \\
8 & $12,750,000$ \\
9 & $13,875,000$ \\
10 & $15,000,000$ \\
\hline
\end{tabular}






Figure 4.1: Linear plot to estimate intermediate CAES unit cost

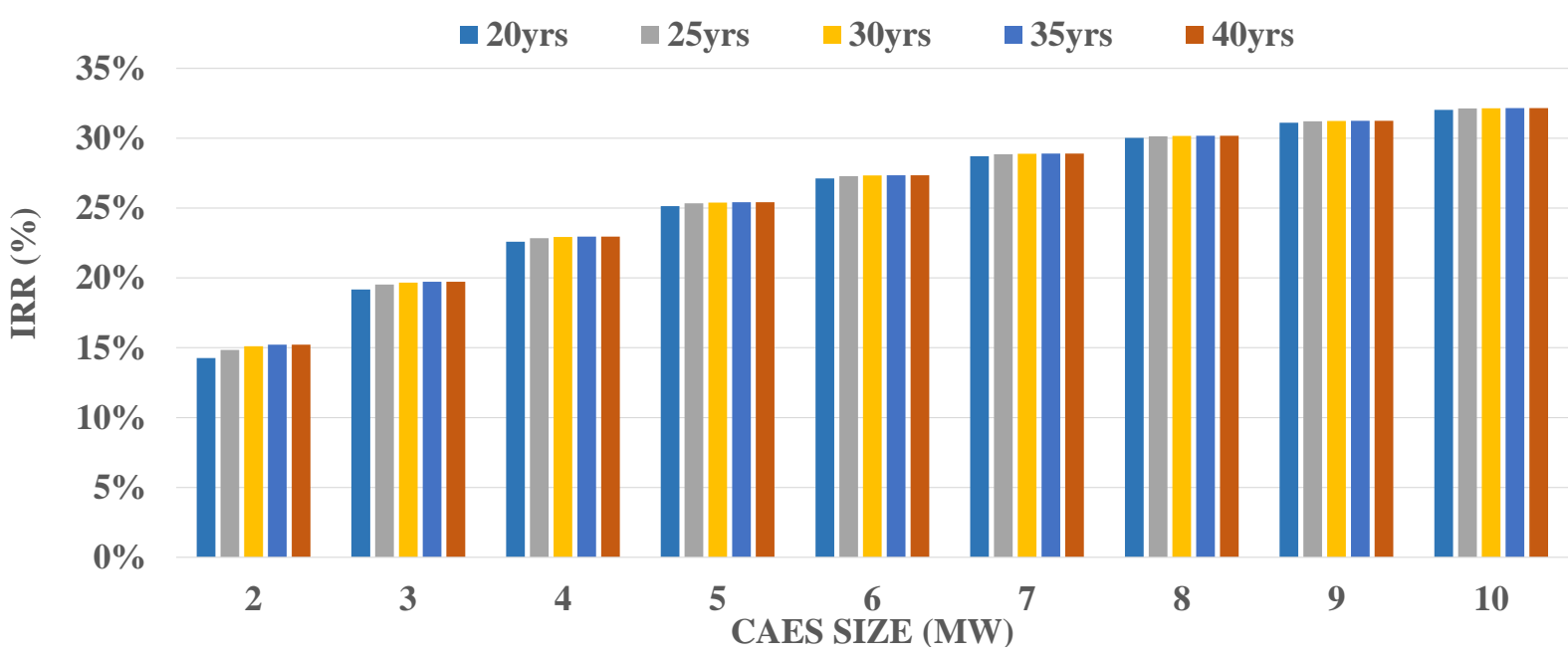

Figure 4.2: IRR results obtained from basic economic analysis.

30 years has an IRR of $15 \%$, which can be considered to be an acceptable proposition. The linearly increasing trend of the IRR from lower CAES ratings to higher ones can be associated with the corresponding assumption of linear capital cost variation with size. 
Since only the GAC is considered, the results obtained from this basic analysis provides insight into the lower bound of the expected profit margin for behind-the-meter SS-CAES.

\subsubsection{Detailed Economic Analysis}

A detailed economic analysis is necessary to capture the variability in the facility's load profile, which is possible by simulation of the optimal operation of the SS-CAES for different unit sizes and life cycles discussed in Chapter 3. The IRR relations presented in (4.1) and (4.2) also apply here.

The base case results are shown in Figure 4.3. In this case, the EnC has been accounted for, which was ignored in the basic analysis. Accordingly, the cost savings from SS-CAES and hence the IRRs obtained from the detailed analysis are higher. Observe that a CAES system of $2 \mathrm{MW} / 4 \mathrm{MWh}$ capacity, even for a low plant life of 25 years, achieved an IRR greater than $15 \%$. This signifies that the industrial customer could save significantly with an SS-CAES at the current electricity rate structure.



Figure 4.3: IRR results of the detailed economic analysis 


\subsection{Sensitivity Analysis}

From the basic and detailed analyses performed, it can be observed that the IRRs for behind-the-meter SS-CAES are affected by factors such as the capacity of the CAES system. Also, since SS-CAES projects are at the development stage, economic uncertainties are relatively high, and therefore, it is necessary to perform a sensitivity analysis to understand the significance of the various parameters affecting CAES investment viability.

\subsubsection{Sensitivity to CAES Capacity}

In Chapter 3, the energy capacity of a 5 MW CAES system was varied over a range of 10 - 30 MWh to gain insight on how the cost reduction was impacted by the size of the storage medium. Figure 3.9 showed that doubling the energy size only resulted in less than $1.1 \%$ savings in the electricity cost, because the CAES facility was only in operation for $5 \mathrm{cp}$ hours to capture the peak demand. Furthermore, from the detailed economic analysis of Section 4.1.2, it is noted that the IRRs are significantly dependent on the CAES power capacity. Hence, it can be deduced that the power capacity of the CAES has a higher impact on the customer's load profile in Ontario than its energy capacity. Accordingly, for subsequent studies, only the power capacity of the CAES is varied for 2 hours fixed discharge duration.

\subsubsection{Sensitivity to GA}

As stated earlier, GA is the major driver of the rising cost of electricity for C\&I customers in Ontario. Furthermore, the previous results of both the basic and detailed economic analysis showed a reasonable IRR even for a CAES system with a lower capacity and cycle life. Hence, sensitivity studies are carried out by considering a reduction in the GAC, in steps of $5 \%$ from the nominal, and the results are shown in Figures 4.4 to 4.8. Note that even for a 10\% reduction in GAC, the IRRs of all the considered CAES sizes and life cycles are above $14 \%$. For a $15 \%$ reduction in GAC, 2 MW/4 MWh SS-CAES system in all the years considered yields an IRR less that $14 \%$. Furthermore, note that for CAES capacities of $3 \mathrm{MW}$ and above, for all life cycles considered, the IRRs are all above $15 \%$. For a $20 \%$ GAC reduction, a $3 \mathrm{MW} / 6 \mathrm{MWh}$ CAES facility with a 20-year life cycle and above yield an IRR of above $15 \%$ and facilities with sizes beyond $5 \mathrm{MW} / 10 \mathrm{MWh}$ for all life cycles, yielded IRRs greater than 15\%. For a possible $25 \%$ reduction in the GAC, the investor must consider CAES capacities of $4 \mathrm{MW}$ and above to achieve an IRR of $15 \%$. Hence, it 


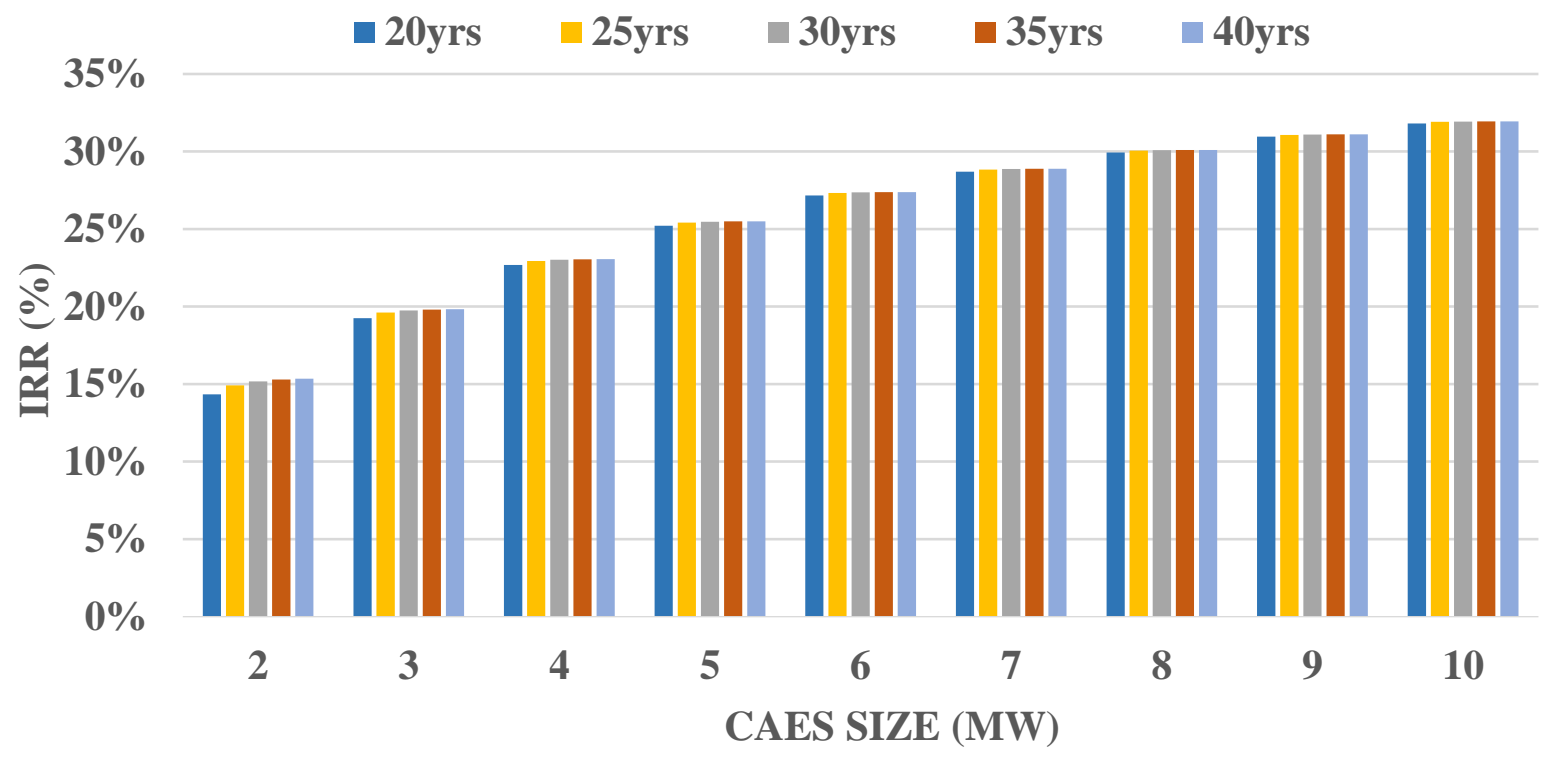

Figure 4.4: IRR results for $5 \%$ reduction in GAC

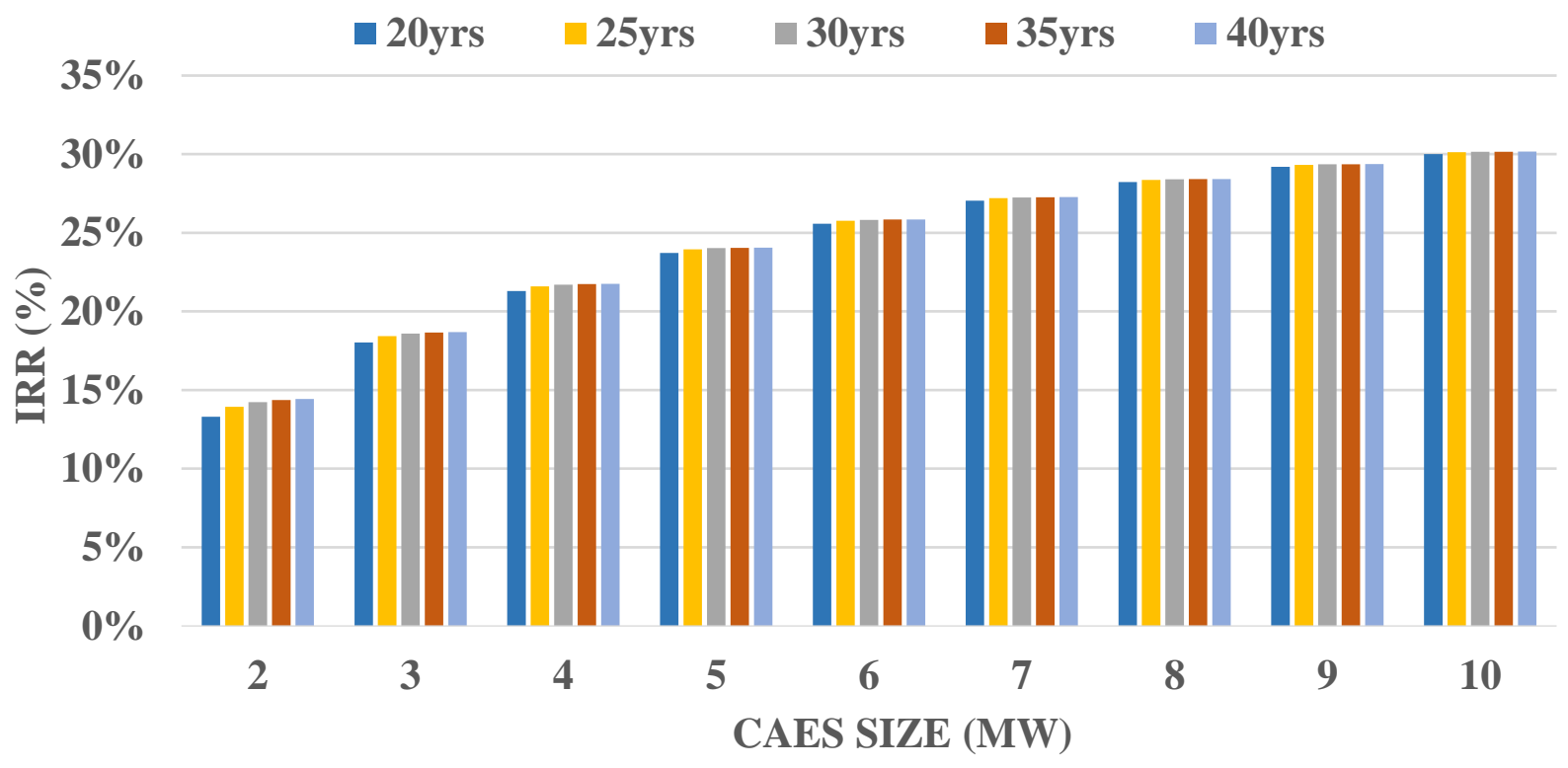

Figure 4.5: IRR Results for $10 \%$ reduction in GAC 
can be concluded that as the GA is reduced or phased out, the investment in SS-CAES becomes less attractive for smaller-size CAES capacities.

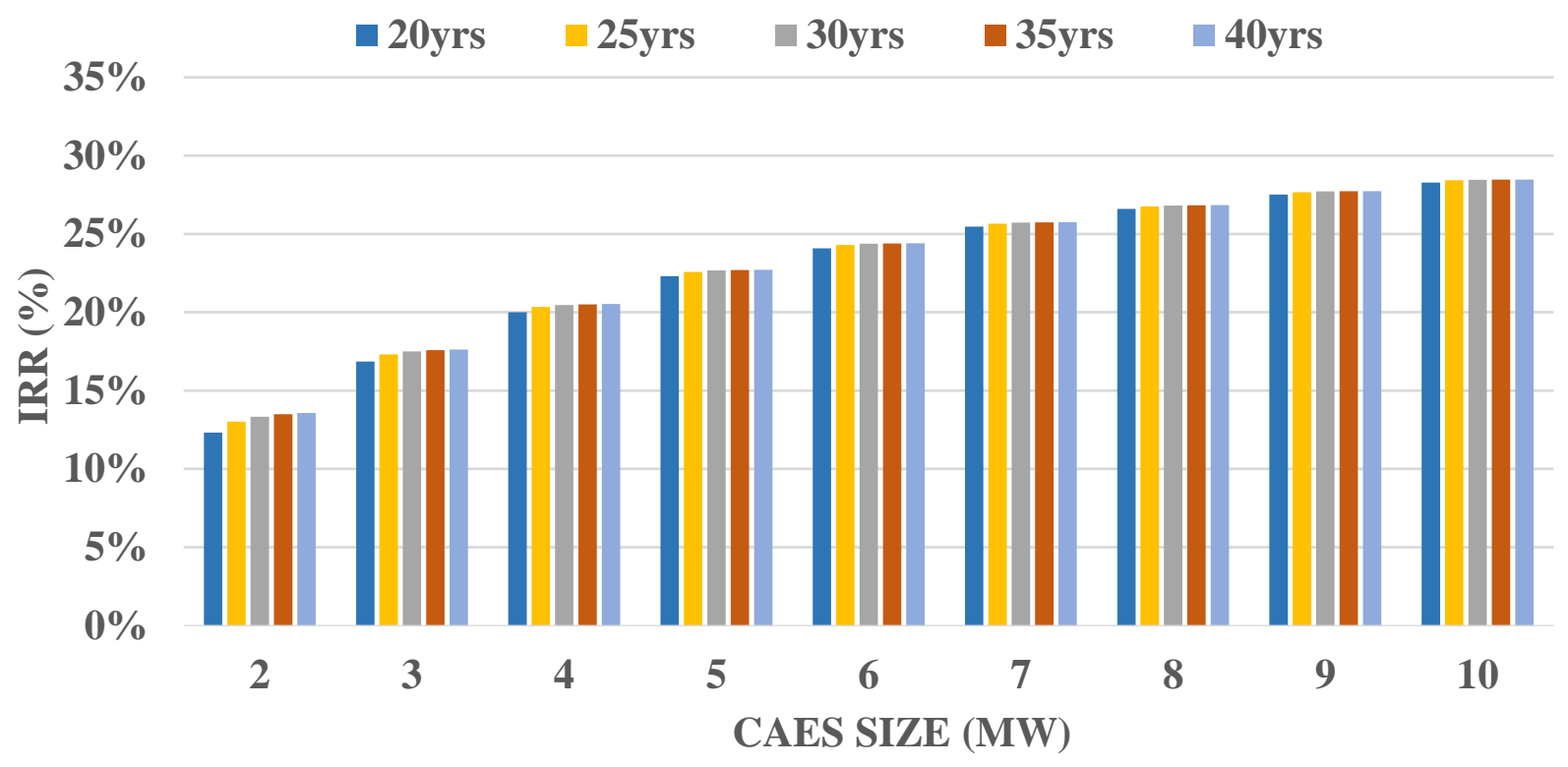

Figure 4.6: IRR results for $15 \%$ reduction in GAC

\subsubsection{Sensitivity to CAES Capital Cost}

There are uncertainties surrounding the capital cost of SS-CAES unit due to the limited number of such projects in existence, and the uniqueness of each project possible design. In the current research work, it is assumed that the customer has an existing well/cavern which can be re-purposed for air storage, which could significantly reduce the capital cost of the CAES project [7]. Most of the available data on CAES unit cost are specifically for large-scale CAES projects; hence taking into account economies of scale, smaller sized CAES systems can be expected to have a higher unit cost. To account for cost uncertainties, the CAES unit cost is varied here by $+\$ 500 / \mathrm{kW}$ from the cost in Table 4.2 .

As can be seen from the results presented in Figures 4.9 to 4.12 , the IRRs linearly decrease as the unit capital cost of the CAES increases. Again, depending on the company's MARR, $3 \mathrm{MW} / 6 \mathrm{MWh}$ CAES capacity and above can be considered to be economically attractive if the unit cost is below the $2,000-3,500 \$ / \mathrm{kW}$ range. For a unit cost range of $2,500-4,000 \$ / \mathrm{kW}$, the investor would need a CAES of $5 \mathrm{MW} / 10 \mathrm{MWh}$ and above for 


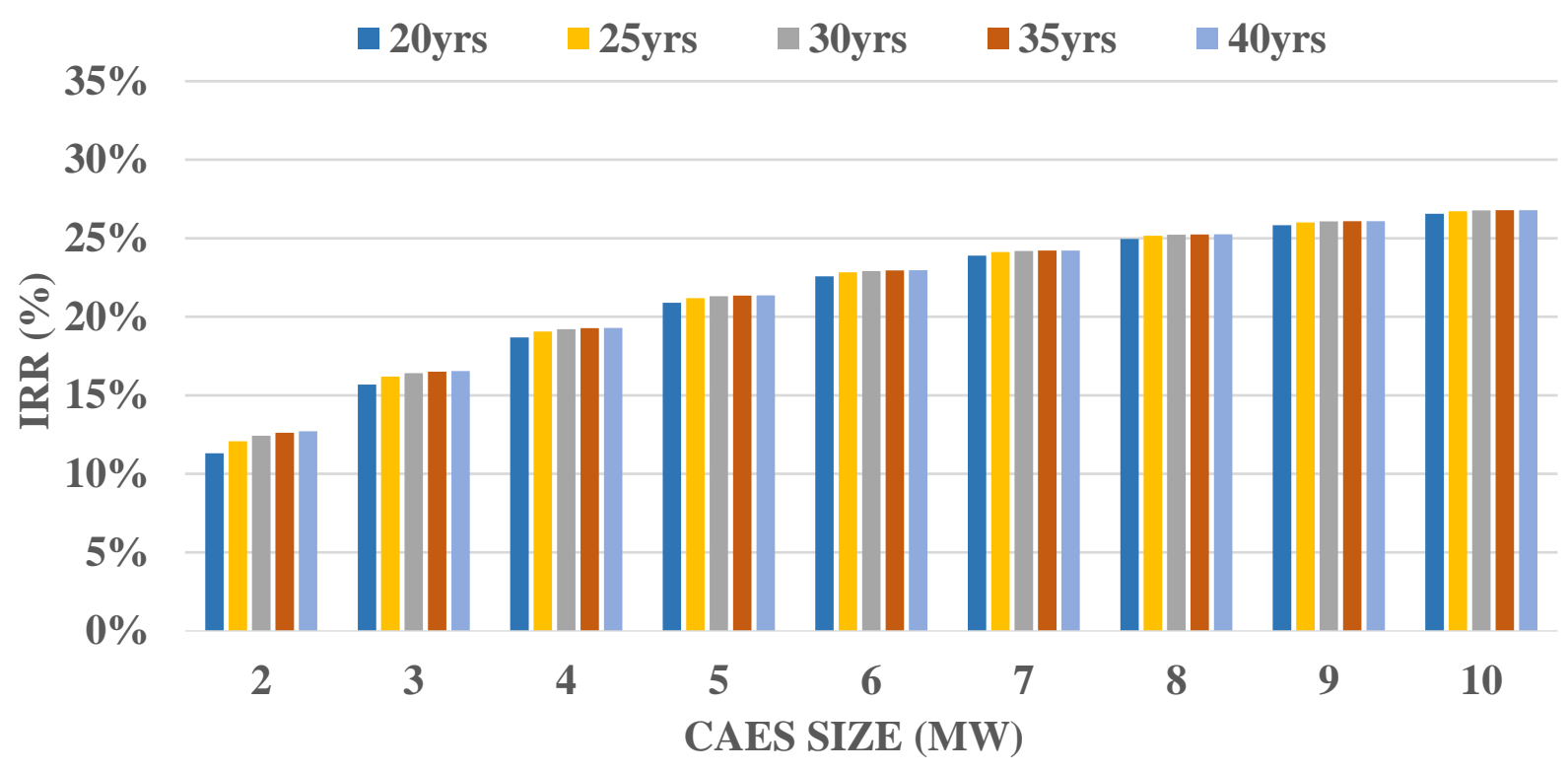

Figure 4.7: IRR results for $20 \%$ reduction in GAC

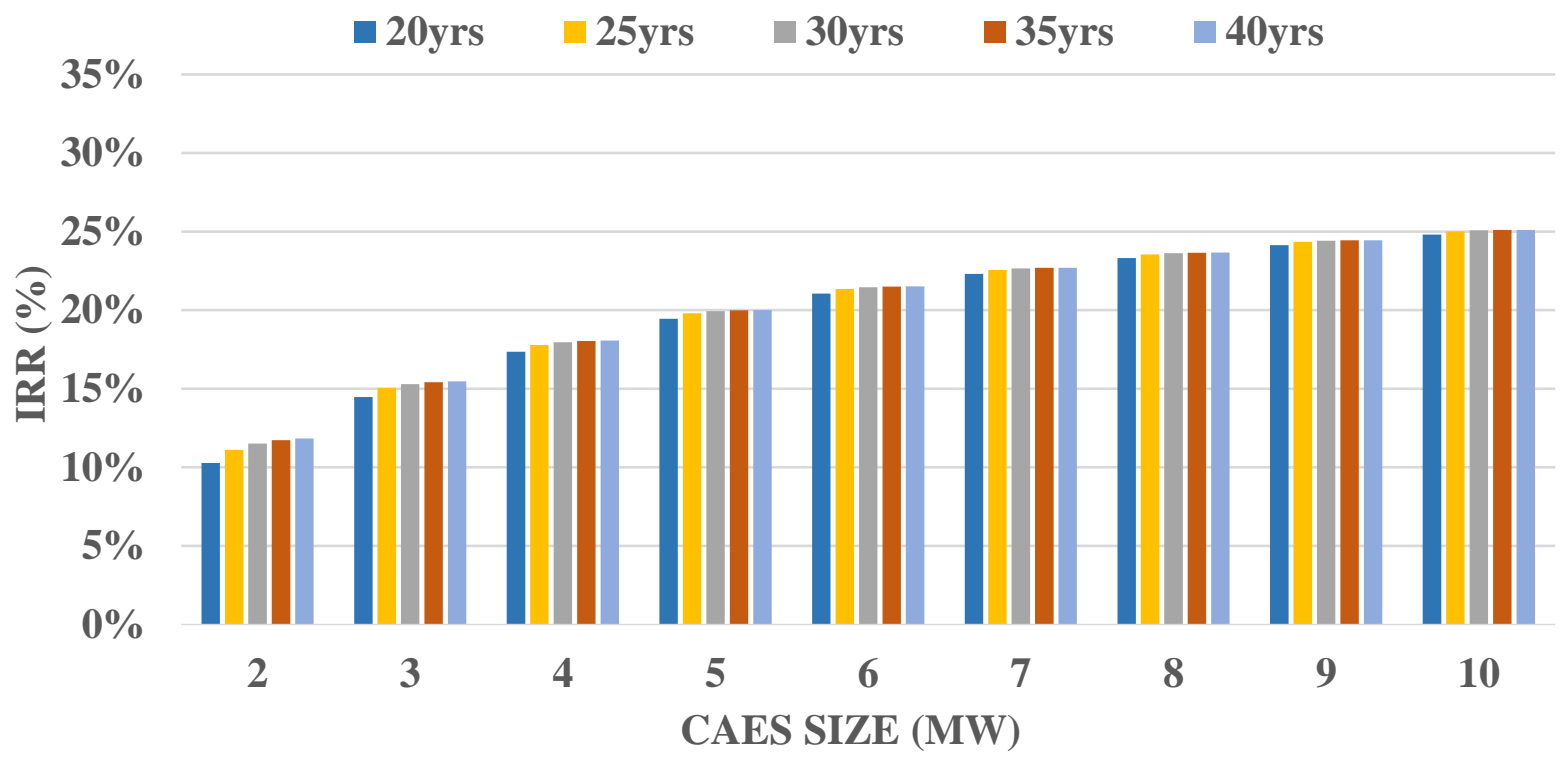

Figure 4.8: IRR results for $25 \%$ reduction in GAC 


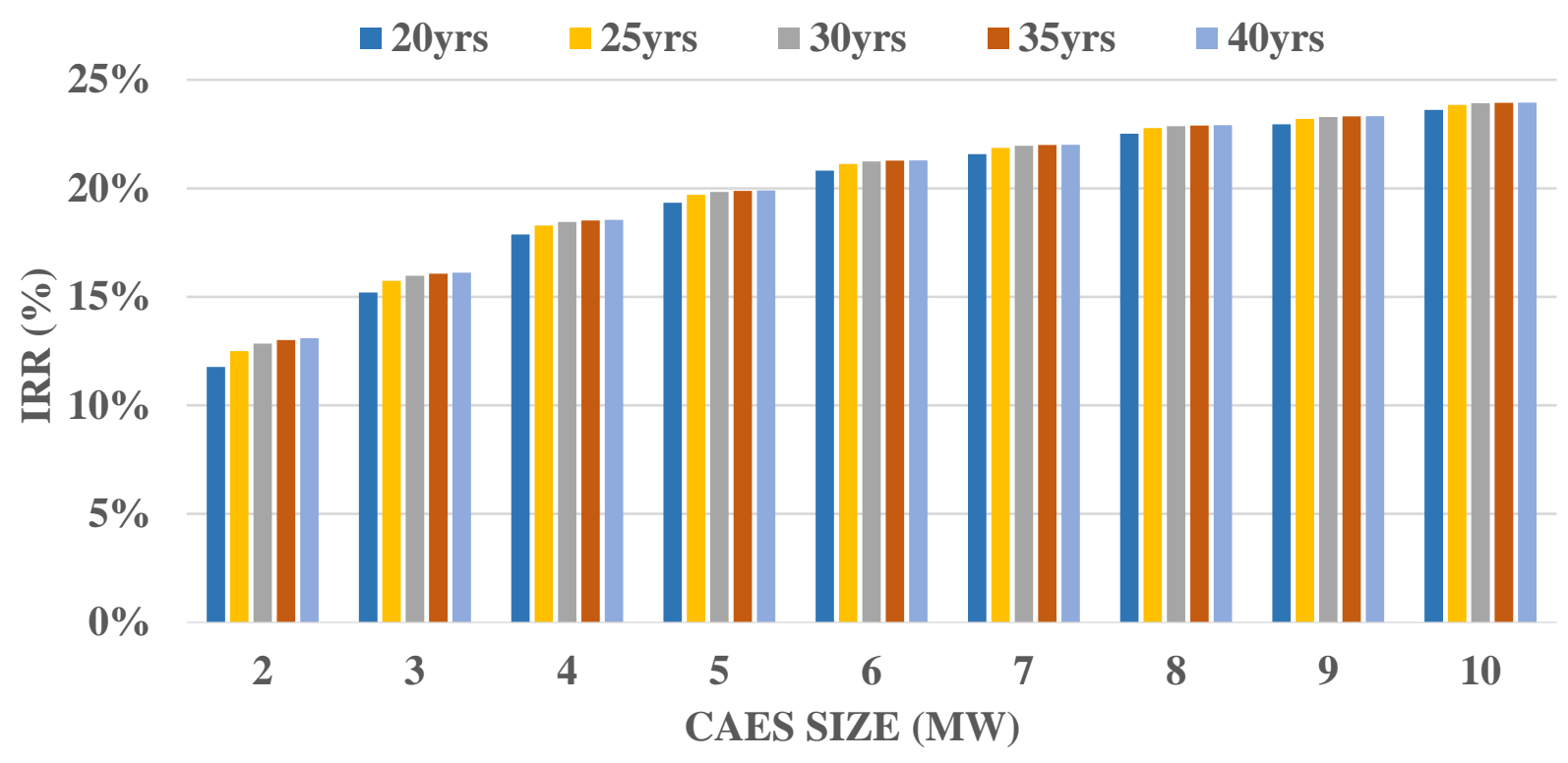

Figure 4.9: Result of CAPEX increases in the range of 2,000-3500 $\$ / \mathrm{kW}$

$25 \%-20 \mathrm{yrs}-25 \mathrm{yrs} \square 30 \mathrm{yrs} \backsim 35 \mathrm{yrs} \square 40 \mathrm{yrs}$



Figure 4.10: Result of CAPEX increases in the range of 2,500-4,000 $\$ / \mathrm{kW}$ 


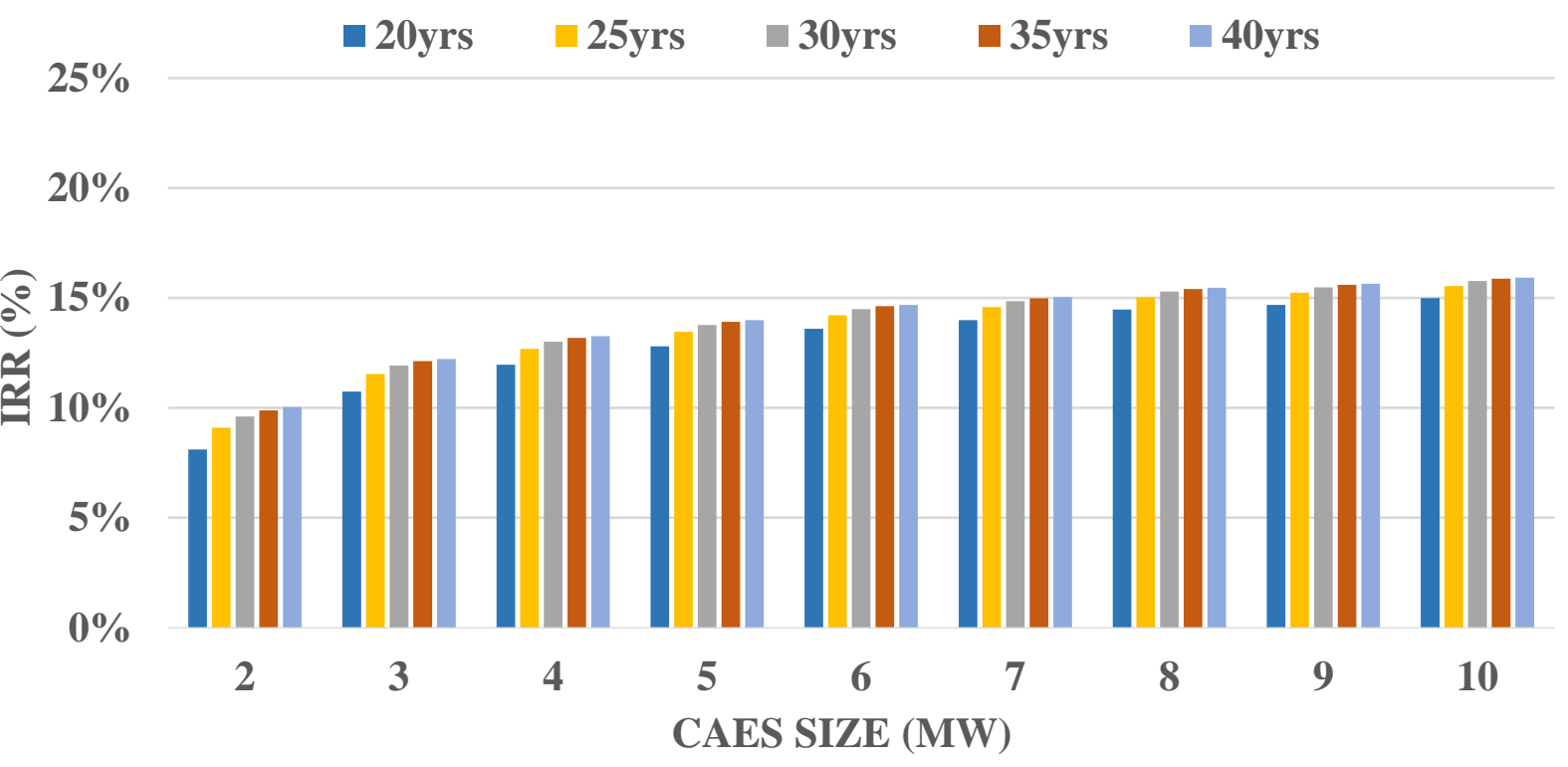

Figure 4.11: Result of CAPEX increases in the range of 3,000-4,500 $\$ / \mathrm{kW}$
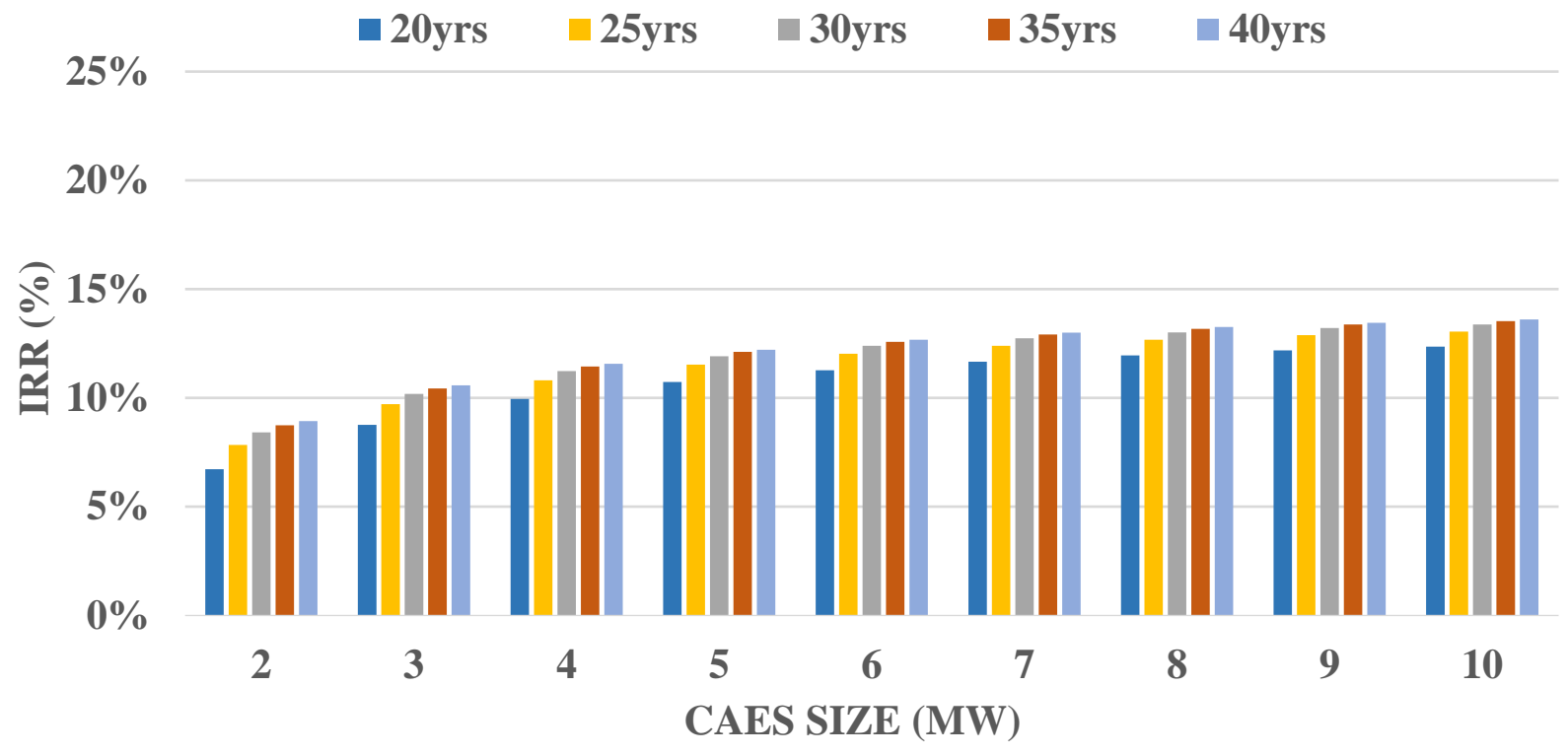

Figure 4.12: Result of CAPEX increases in the range of 3,500-5,000 $\$ / \mathrm{kW}$. 
reasonable IRRs from the SS-CAES project. For a 3,000 - 4,500 $\$ / \mathrm{kW}$ unit cost range, investment in the SS-CAES makes economic sense when the system capacity exceeds 6 $\mathrm{MW} / 12 \mathrm{MWh}$ to attain an IRR of $14 \%$. The IRRs for a unit cost range of 3,500 - 5,000 $\$ / \mathrm{kW}$ in all the different CAES capacities and life cycles considered have IRRs of less than $14 \%$, which is not attractive.

\subsection{Comparison with BES}

An economic comparison of two different storage technologies is difficult because of the unique characteristics of each technology. Another hurdle is obtaining CAPEX costs for each technology, since this information is considered confidential among suppliers and integrators [60].

The model developed in this work can be used to evaluate the economic viability of behind-the-meter BES with just an additional constraint to account for the maximum allowable depth of discharge (DoD), which is ignored for the CAES model since the CAES facility can discharge its full capacity. To prolong the life of the BES, the maximum DoD of the battery is usually set to be less than 100\%, in most cases, between $50 \%$ to $90 \%$ depending on application [61]. The maximum discharge power from the BES is therefore limited by its DoD which reduces the amount of power the BES can shave at a given time. Since the realizable reduction in GA is dependent on the maximum discharge power capacity of the storage, the limit imposed by the BES DoD will shrink the savings from such investments. On the other hand, since CAES can utilize the full range of charge on the system more cost reduction for the customer can be expected.

A unit capital cost range of $\$ 1500 / \mathrm{kW}-\$ 3000 / \mathrm{kW}[7]$ is considered for CAES in the present work, whereas the unit capital cost of BES depending on the battery technology ranges from $\$ 1500 / \mathrm{kW}$ to $\$ 4000 / \mathrm{kW}[7,61]$. Thus, CAES can be considered a low cost technology when compared with BES particularly where existing infrastructure such as a cavern can be repurposed.

CAES has unlimited cycle stability and can be discharged from $100 \%$ to $0 \%$ without compromising the longevity of the system [7,61]. On the other hand, BES suffers from degradation, and when constantly cycled the lifespan is reduced, which has a negative impact on the economics of the project. As can be observed from the IRR results of the SS-CAES economic analysis, projects with longer lifespan achieved higher IRR values. The lifetime of CAES systemS given by most authors and technology developers is between 25 to 40 years; BES technologies, on the other hand, have a relatively limited lifetime, with 
manufacturers claiming 8 to 15 years of operating life for the popular Li-Ion battery; however, this figure varies significantly with battery usage [61].

Another added advantage of CAES over BES is that it can be designed to charge and discharge simultaneously. Although this is not considered is the present work, it would increase the customer's return on CAES investment, as the owner would have the flexibility to use the CAES facility for multiple services at the same time.

In conclusion, CAES technology presents advantages over BES for customer's load management where high discharge power is required from the storage unit to defray the high-peak power prices. In addition, the longer life cycle and unlimited cycling capability of CAES is advantageous with respect to BES systems.

\subsection{Summary}

This chapter examined the economic valuation of behind-the-meter SS-CAES systems on an industrial customer's facility for load management, using the historical load data of a real Class A customer participating in the ICI program.

First, a simplified basic analysis was carried out to gain insight into the possible lower bound of achievable IRR, and the results showed a close similarity with the detailed economic analysis. Sensitivity analyses were then carried out to estimate the effects of CAES capacity, GAC, and $C A P E X$ on the economics of behind-the-meter SS-CAES systems for customer load management, concluding that the driving factors for the economic viability were the GAC and the $C A P E X$ of the CAES system.

A comparison on the economics of CAES versus BES for customer's load management is discussed as well and CAES presents more advantages than BES for electricity cost reduction of an industrial customer.

It can be concluded that SS-CAES for load management applications to reduce electricity costs is economically attractive in the current Ontario market structure. However, depending on the company's MARR and budget constraints, plus the facility's demand profile, SS-CAES with higher capacity yielded better economic values in all the cases considered. 


\section{Chapter 5}

\section{Conclusions, Contributions and Future Work}

\subsection{Summary and Conclusions}

ESS has been identified as one of the viable solutions to managing the load of C\&I customers to keep electricity costs at a minimum. The research presented in this thesis focused on the optimal operation and economic analysis of using behind-the-meter SS-CAES to manage the load of an industrial customer in Ontario that is participating in the ICI program. The customer has been assumed to have abandoned wells/caverns that can be re-purposed for air storage.

In Chapter 1, the motivations of this research, a brief review of the literature related to CAES applications and customer's load management schemes, together with the research objectives were presented. In Chapter 2, background material relevant for the development of the research work was presented. Thus, an overview of ESS technologies, focusing on their classification and applications at different levels in power systems was presented. A review of CAES systems was given, outlining the basic components, operating principles, types and potential use cases. Finally, the electricity pricing structure in Ontario was presented with a focus on the Class A customers, including the GA which is the major driver for the increasing electricity costs in the province.

In Chapter 3, an operations model of SS-CAES to manage the customer's load during the system peak hours, was formulated as an optimization problem. The one-year hourly load data of a real industrial customer participating in the ICI program, and the HOEP 
data obtained from the IESO website, alongside CAES performance parameters obtained from different related research works, constituted the input parameters into the model. The results of the developed MILP model, which was solved using CPLEX in GAMS, were presented and discussed.

In Chapter 4, the financial plausibility of behind-the-meter SS-CAES for a facility load management was investigated through an economic analysis taking into account the investment cost of behind-the-meter SS-CAES. Simplified basic analysis alongside detailed analysis were carried out for different CAES sizes and life cycles. The effects of some parameters that can influence a behind-the-meter SS-CAES investment were evaluated through a sensitivity analysis, and the IRR results were presented and discussed.

The main conclusions and findings of this thesis are as follows:

- SS-CAES installed behind-the-meter on the facility's premise for reducing the electricity cost of the customer provides a viable economical solution for the current Ontario's electricity market structure, or jurisdiction with similar high capacity costs.

- A larger discharge power capacity $(\mathrm{kW})$ of the SS-CAES makes more economic sense than energy capacity ( $\mathrm{kWh}$ ) since the GAC of such customers are based on their load contribution during the top peak hours. Furthermore, the customer should consider cost reductions with higher capacity due to economies of scale to make investment decisions.

- In the current Ontario's electricity rate structure, the costs of the CAES project and GA are the most influential parameters for economic deployment of SS-CAES, as observed from the sensitivity analysis.

\subsection{Contributions}

The following are the contributions of the presented research work:

- Developed and validated a mathematical model to manage the operation of a customer's facility equipped with a behind-the-meter SS-CAES. The proposed optimization model determined the minimum electricity costs, the SS-CAES energy output, and the corresponding charging and discharging decisions for the facility.

- Performed simplified and detailed economic analysis of different SS-CAES sizes to determine the SS-CAES capacity that yield reasonable IRRs. 
- Performed a sensitivity analysis of the interactions between financial viability of behind-the-meter SS-CAES project, identifying key parameters that would influence the investor's decisions.

\subsection{Future Work}

Based on the research work presented in this thesis, the following research subjects would be worthwhile:

- In the presented research work, a fixed parameter model is used which takes no account of the thermodynamic characteristics of CAES, and therefore the profit may have been over-estimated. An investigation on the effect of the system thermodynamics on the economics of behind-the-meter SS-CAES and comparison with fixed parameters model would be of interest.

- A perfect foresight of the occurrence time of the Ontario 5cp hours is assumed in this work, but in reality, predicting the system peak hours is challenging and it may worth the effort to incorporate a prediction model in the economic analysis to improve the performance of the method proposed in this research.

- Aside the direct load management of the investor's load to reduce electricity costs, a behind-the-meter SS-CAES can provide other benefits to the investor such as aiding the integration of renewable sources and increasing the self-consumption of on-site renewable generation, getting revenue from arbitrage, and participating in capacity market alongside demand response. Hence, a techno-economic analysis of "stacked services" using SS-CAES would be worthwhile, considering that the investor could size up the CAES capacity to increase overall revenue.

- In the wake of the current reforms in the Ontario electricity market design, it would be interesting to investigate the impact this will have on the GA and thus the investments in behind-the-meter SS-CAES. 


\section{References}

[1] R. McKitrick and E. Aliakbari, "Rising Electricity Costs and Declining Employment in Ontario's Manufacturing Sector," October 2017. [Online]. Available: https://www.fraserinstitute.org/studies/ rising-electricity-costs-and-declining-employment-in-ontarios-manufacturing-sector

[2] EnergyWatch, "Peak Load Management Strategies," 2018. [Online]. Available: https://energywatch-inc.com/peak-load-management-strategies/

[3] IESO, "What is Global Adjustment?" [Accessed on 2019/02/25]. [Online]. Available: http://www.ieso.ca/en/Learn/Electricity-Pricing/What-is-Global-Adjustment

[4] C. DiRuscio and T. Hilbig, "Large Electricity Consumer? Take Control of your Global Adjustment," November 2012. [Online]. Available: https://www.energy-manager.ca/ utilities/large-electricity-consumer-take-control-of-your-global-adjustment-1623/

[5] M. Uddin, M. F. Romlie, M. F. Abdullah, S. A. Halim, A. H. A. Bakar, and T. C. Kwang, "A Review on Peak Load Shaving Strategies," Renewable and Sustainable Energy Reviews, vol. 82, pp. 3323 - 3332, 2018.

[6] N.-K. C. Nair and N. Garimella, "Battery Energy Storage Systems: Assessment for Small-Scale Renewable Energy Integration," Energy and Buildings, vol. 42, no. 11, pp. 2124 - 2130, 2010. [Online]. Available: http://www.sciencedirect.com/science/ article/pii/S0378778810002185

[7] Hydrostor, "Advanced Compressed Air Energy Storage," Australian Energy Storage Association Conference - Adelaide, SA, 2018. [Online]. Available: https://australianenergystorage.com.au/wordpress/wp-content/uploads/2018/ 06/1145-Thur-CR-Norman.pdf 
[8] H. Ibrahim, K. Belmokhtar, and M. Ghandour, "Investigation of Usage of Compressed Air Energy Storage for Power Generation System Improving - Application in a Microgrid Integrating Wind Energy," Energy Procedia, vol. 73, pp. 305 - 316, 2015, 9th International Renewable Energy Storage Conference, IRES 2015.

[9] S. Succar and R. Williams, "Compressed Air Energy Storage: Theory, Resources, And Applications for Wind Power," Energy Systems Analysis Group , Princeton Environmental Institute, 012008.

[10] J. Wang, K. Lu, L. Ma, J. Wang, M. Dooner, S. Miao, J. Li, and D. Wang, "Overview of Compressed Air Energy Storage and Technology Development," Energies, vol. 10, no. 7, July 2017.

[11] R. B. Schainker and M. Nakhamkin, "Compressed-Air Energy Storage (CAES): Overview, Performance and Cost Data for 25MW-220MW Plants," IEEE Power Engineering Review, vol. PER-5, no. 4, pp. 32-33, April 1985.

[12] A. Sharma, H. Chiu, F. Ahrens, R. Ahluwalia, and K. Ragsdell, "Design of Optimum Compressed Air Energy-Storage Systems," Energy, vol. 4, no. 2, pp. 201 - 216, 1979, 1978 Midwest Energy Conference.

[13] A. J. Giramonti, R. D. Lessard, W. A. Blecher, and E. B. Smith, "Conceptual Design of Compressed Air Energy Storage Electric Power Systems," Applied Energy, vol. 4, no. 4, pp. $231-249,1978$.

[14] I. Glendenning, "Long-term Prospects for Compressed Air Storage," Applied Energy, vol. 2, no. 1, pp. $39-56,1976$.

[15] J. Wang, L. Ma, K. Lu, S. Miao, D. Wang, and J. Wang, "Current Research and Development trend of Compressed Air Energy Storage," Systems Science 8 Control Engineering, vol. 5, no. 1, pp. 434-448, 2017.

[16] "Applications of Energy Storage Technology," Energy Storage Association, 2019, [Accessed on 2019-02-22]. [Online]. Available: http://energystorage.org/ energy-storage/applications-energy-storage-technology

[17] L. Chen, T. Zheng, S. Mei, X. Xue, B. Liu, and Q. Lu, "Review and Prospect of Compressed Air Energy Storage System," Journal of Modern Power Systems and Clean Energy, vol. 4, no. 4, pp. 529-541, Oct 2016. 
[18] H. Chen, X. Zhang, J. Liu, and C. Tan, "Compressed Air Energy Storage," in Energy Storage-Technologies and Applications, A. F. Zobaa, Ed. Intech, January 2013, ch. 4, pp. 101-112.

[19] J. M. Eyer and G. P. Corey, "Energy Storage for the Electricity Grid : Benefits and Market Potential Assessment Guide : a study for the DOE Energy Storage Systems Program," United States, February 2010.

[20] K. Bradbury, L. Pratson, and D. Patiño-Echeverri, "Economic Viability of Energy Storage Systems Based on Price Arbitrage Potential in real-time U.S. Electricity Markets," Applied Energy, vol. 114, pp. 512 - 519, 2014.

[21] R. Sioshansi, P. Denholm, T. Jenkin, and J. Weiss, "Estimating the Value of Electricity Storage in PJM: Arbitrage and some Welfare Effects," Energy Economics, vol. 31, no. 2, pp. $269-277,2009$.

[22] R. Walawalkar, J. Apt, and R. Mancini, "Economics of Electric Energy Storage for Energy Arbitrage and Regulation in New York," Energy Policy, vol. 35, no. 4, pp. $2558-2568,2007$.

[23] E. Drury, P. Denholm, and R. Sioshansi, "The Value of Compressed Air Energy Storage in Energy and Reserve Markets," Energy, vol. 36, no. 8, pp. 4959 - 4973, 2011.

[24] C. Bullough, C. Gatzen, C. Jakiel, M. Koller, A. Nowi, and S. Zunft, "Advanced Adiabatic Compressed Air Energy Storage for the Integration of Wind Energy," European Wind Energy Conference London, UK, January 2004.

[25] N. S. Hasan, M. Y. Hassan, M. S. Majid, and H. A. Rahman, "Review of Storage Schemes for Wind Energy Systems," Renewable and Sustainable Energy Reviews, vol. 21, pp. $237-247,2013$.

[26] B. Tammam, I. Adrian, Y. Rafic, and P. Jean, "A new Multi-hybrid Power System for Grid-disconnected areas Wind-Diesel-Compressed Air Energy Storage," in International Conference on Renewable Energies for Developing Countries (REDEC), Nov 2012, pp. 1-8.

[27] C. Harris, J. Meyers, and M. Webber, "A Unit Commitment Study of the Application of Energy Storage toward the Integration of Renewable Generation," Journal of Renewable and Sustainable Energy, vol. 4, February 2012. 
[28] C. Krupke, J. Wang, J. Clarke, and X. Luo, "Modeling and Experimental Study of a Wind Turbine System in Hybrid Connection With Compressed Air Energy Storage," IEEE Transactions on Energy Conversion, vol. 32, no. 1, pp. 137-145, March 2017.

[29] J. D. Wojcik and J. Wang, "Feasibility Study of Combined Cycle Gas Turbine (CCGT) Power Plant Integration with Adiabatic Compressed Air Energy Storage (ACAES)," Applied Energy, vol. 221, pp. 477-489, 2018.

[30] Z. Hu, F. Zhang, and B. Li, "Transmission Expansion Planning Considering the Deployment of Energy Storage Systems," in IEEE Power and Energy Society General Meeting, July 2012, pp. 1-6.

[31] F. Zhang, Z. Hu, and Y. Song, "Mixed-Integer Linear Model for Transmission Expansion Planning with Line Losses and Energy Storage Systems," IET Generation, Transmission Distribution, vol. 7, no. 8, pp. 919-928, Aug 2013.

[32] D. Wu, M. Kintner-Meyer, , and P. Balducci, "Economic Analysis and Optimal Sizing for Behind-the-Meter Battery Storage," in IEEE Power and Energy Society General Meeting (PESGM), July 2016, pp. 1-5.

[33] "Electric Load Management in Industry," Electric Load Management in Industry working group UIE, 2009. [Online]. Available: http://www.leonardo-energy.org/

[34] A. Oudalov, R. Cherkaoui, and A. Beguin, "Sizing and Optimal Operation of Battery Energy Storage System for Peak Shaving Application," in IEEE Lausanne Power Tech., July 2007, pp. 621-625.

[35] O. Lavrova, F. Cheng, S. Abdollahy, H. Barsun, A. Mammoli, D. Dreisigmayer, S. Willard, B. Arellano, and C. van Zeyl, "Analysis of Battery Storage Utilization for Load Shifting and Peak Smoothing on a Distribution Feeder in New Mexico," in IEEE PES Innovative Smart Grid Technologies (ISGT), Jan 2012, pp. 1-6.

[36] M. Zheng, C. J. Meinrenken, and K. S. Lackner, "Smart Households: Dispatch Strategies and Economic Analysis of Distributed Energy Storage for Residential Peak Shaving," Applied Energy, vol. 147, pp. 246-257, 2015.

[37] J. Leadbetter and L. Swan, "Battery Storage System for Residential Electricity Peak Demand Shaving," Energy and Buildings, vol. 55, pp. 685 - 692, 2012, cool Roofs, Cool Pavements, Cool Cities, and Cool World. 
[38] E. Reihani, M. Motalleb, R. Ghorbani, and L. S. Saoud, "Load Peak Shaving and Power Smoothing of a Distribution Grid with High Renewable Energy Penetration," Renewable Energy, vol. 86, pp. 1372-1379, 2016.

[39] K. H. Chua, Y. S. Lim, and S. Morris, "Energy Storage System for Peak Shaving," International Journal of Energy Sector Management, vol. 10, no. 1, pp. 3-18, 2016.

[40] C. Lu, H. Xu, X. Pan, and J. Song, "Optimal Sizing and Control of Battery Energy Storage System for Peak Load Shaving," Energies, vol. 7, pp. 8396-8410, 122014.

[41] C. A. Babu and S. Ashok, "Peak Load Management in Electrolytic Process Industries," IEEE Transactions on Power Systems, vol. 23, no. 2, pp. 399-405, May 2008.

[42] T. A. Nguyen and R. H. Byrne, "Maximizing the Cost-Savings for Time-of-Use and Net-Metering Customers using Behind-the-Meter Energy Storage Systems," in North American Power Symposium (NAPS), Sep. 2017, pp. 1-6.

[43] J. Neubauer and M. Simpson, "Deployment of Behind-The-Meter Energy Storage for Demand Charge Reduction," United States, January 2015. [Online]. Available: https://www.nrel.gov/docs/fy15osti/63162.pdf

[44] W. Lee, J. Jung, and B. O. Kang, "Cost-Benefit Analysis for Industrial CustomersInstalled Energy Storage System in South Korea," in IEEE Innovative Smart Grid Technologies - Asia (ISGT Asia), May 2018, pp. 470-474.

[45] H. Chen, T. N. Cong, W. Yang, C. Tan, Y. Li, and Y. Ding, "Progress in Electrical Energy Storage System: A Critical Review," Progress in Natural Science, vol. 19, no. 3, pp. 291-312, 2009.

[46] "Electric Energy Storage Systems," Quanta Technology, 2013. [Online]. Available: https://quanta-technology.com/resource-documents/electric-energy-storage-systems

[47] X. Luo, J. Wang, M. Dooner, and J. Clarke, "Overview of Current Development in Electrical Energy Storage Technologies and the Application Potential in Power System Operation," Applied Energy, vol. 137, pp. 511 - 536, 2015.

[48] T. M. Gür, "Review of Electrical Energy Storage Technologies, Materials and Systems: Challenges and Prospects for Large-Scale Grid Storage," Energy Environ. Sci., vol. 11, pp. 2696-2767, 2018. 
[49] D. Akinyele and R. Rayudu, "Review of Energy Storage Technologies for Sustainable Power Networks," Sustainable Energy Technologies and Assessments, vol. 8, pp. 74 91, 2014.

[50] D. T. Bradshaw, "Pumped Hydroelectric Storage (PHS) and Compressed Air Energy Storage (CAES)," in Power Engineering Society Summer Meeting (Cat. No.00CH37134), vol. 3, July 2000, pp. 1551-1573.

[51] L. Li, W. Liang, H. Lian, J. Yang, and M. Dusseault, "Compressed Air Energy Storage: Characteristics, Basic Principles, and Geological Considerations," Advances in GeoEnergy Research, vol. 2, March 2018.

[52] B. Cleary, A. Duffy, A. OConnor, M. Conlon, and V. Fthenakis, "Assessing the Economic Benefits of Compressed Air Energy Storage for Mitigating Wind Curtailment," IEEE Transactions on Sustainable Energy, vol. 6, no. 3, pp. 1021-1028, July 2015.

[53] E. Bozzolani, "Techno-Economic Analysis of Compressed Air Energy Storage systems," Master's Thesis, Cranfield University, 2010.

[54] HydroQuébec. Comparison of Electricity Prices in Major North American Cities. [Online]. Available: http://www.hydroquebec.com/data/documents-donnees/pdf/ comparison-electricity-prices.pdf

[55] IESO, "Guide to Wholesale Electricity Charges." [Online]. Available: http://www. ieso.ca/Sector-Participants/Settlements/Guide-to-Wholesale-Electricity-Charges

[56] R. E. Rosenthal, "GAMS - A User's Guide," May 2015. [Online]. Available: http://www.gams.com/dd/docs/bigdocs/GAMSUsersGuide.pdf

[57] A. A. Akhil, G. Huff, A. B. Currier, J. Hernandez, D. A. Bender, B. C. Kaun, D. M. Rastler, S. B. Chen, A. L. Cotter, D. T. Bradshaw, W. D. Gauntlett, J. Eyer, T. Olinsky-Paul, M. Ellison, and S. Schoenung, "Electricity Storage Handbook," DOE/EPRI in Collaboration with NRECA, United States, September 2016.

[58] K. K. Humphreys, Jelen's Cost and Optimization Engineering, 3rd ed. New York: McGraw-Hill, 1991, pp. 103-135.

[59] L. H. J. and M. D. N., The Selection Process for Capital Projects. New York: J. Wiley \& Sons, 1993, pp. 262-264.

[60] B. Zakeri and S. Syri, "Electrical Energy Storage Systems: A Comparative Life Cycle Cost Analysis," Renewable and Sustainable Energy Reviews, vol. 42, 112014. 
[61] A. Chatzivasileiadi, E. Ampatzi, and I. Knight, "Characteristics of Ectrical Energy Storage Technologies and their Applications in Buildings," Renewable and Sustainable Energy Reviews, vol. 25, pp. $814-830,2013$. 